\title{
NMDA Receptor Agonist and Antagonists Alter Retinal Ganglion Cell Arbor Structure in the Developing Frog Retinotectal Projection
}

\author{
Hollis T. Cline and Martha Constantine-Paton \\ Biology Department, Yale University, New Haven, Connecticut 06511
}

The development of sensory maps is thought to require an activity-dependent structural rearrangement of afferent terminal arbors within the CNS which recreates the topographic relations of sensory somata present in the periphery. In the frog retinotectal projection, activation of the NMDA receptor plays a role in this structural plasticity. Exposure of the optic tectum of tadpoles to NMDA receptor antagonists results in a rearrangement of retinal ganglion cell arbors so that their organization into a topographic projection and eye-specific stripes is disrupted (Cline et al., 1987; Cline and ConstantinePaton, 1989). Exposure of the optic tectum to the receptor agonist, NMDA, increases the eye-specific segregation of these arbors (Cline et al., 1987).

We examined the projection of the supernumerary retina and the morphology of individual retinal afferent arbors of untreated, NMDA-treated, APV-treated, MK801-treated, and MK801/NMDA-treated 3-eyed tadpoles and young postmetamorphic frogs in an effort to understand how NMDA receptor activation is involved in the growth and ordering of retinal arbors. Treatments with MK801 in combination with NMDA resulted in a desegregation of eye-specific stripes, whereas treatments with MK801 or NMDA alone did not. As reported previously, APV treatment resulted in stripe desegregation without increasing the tangential area (measured from 2-dimensional drawings) of the terminal arbors. However, a detailed analysis revealed that the APV-treated tadpole arbors have $35 \%$ reduction in branch density (branch tips/area) compared to untreated 3-eyed tadpole arbors. We treated the optic tectum with a range of concentrations of NMDA prepared in the slow-release plastic Elvax. NMDA at $10^{-4} \mathrm{M}$ in Elvax was the optimal concentration to produce the sharpening of stripe borders. Exposure of the tectum to NMDA at $10^{-6} \mathrm{M}$ in Elvax produced no change in the stripe pattern, while $10^{-2} \mathrm{M}$ NMDA in Elvax resulted in beading of the arbors. At the optimal concentration NMDA treatment results in a $75 \%$ reduction in the number of axons crossing from a stripe to an interstripe zone. Drawings of individual HRP-labeled, NMDA-treated arbors demonstrate that they have fewer branch points and fewer branch tips. NMDA treatment reduced arbor density by approximately $50 \%$. Arbors drawn from untreated postmetamorphic frogs have twice the branch

Received Aug. 21, 1989; revised Oct. 9, 1989; accepted Oct. 25, 1989

We are grateful to Liz Debski and Daniela Bonefede for fruitful discussions The MK801 was a gift from Merck \& Co. This work was supported by National Institutes of Health grants EY05818 to H.T.C. and EY06039 to M.C.-P.

Correspondence should be addressed to Dr. Hollis T. Cline at her present address: Department of Physiology and Biophysics, The University of Iowa, 5-660 Bowen Science Building, Iowa City, IA 52242.

Copyright (C) 1990 Society for Neuroscience $0270-6474 / 90 / 041197-20 \$ 02.00 / 0$ density of arbors from untreated tadpoles. NMDA treatment in these animals reduced the branch density by $55 \%$, comparable to the reduction seen in tadpole branch density.

Our data support a specific hypothesis for NMDA receptor involvement in the activity-dependent structural refinement process within the developing retinotectal projection. We suggest that the NMDA receptor activation by afferents with correlated activity patterns triggers a process that stabilizes coactive synapses. In addition, we suggest that the maintenance of an arbor branch requires a minimum density of stable synapses and that the stabilization process is associated with a local inhibition of branch initiation within the continuously remodeling terminal. In this way, the degree of NMDA receptor activation and synapse stabilization could influence the growth and morphology of the arbors.

Patterned activity has been implicated in organizing the final positions of afferent terminal arbors during the development of sensory projections in the central nervous system (CNS) (Whitelaw and Cowan, 1981; Udin and Fawcett, 1988; Miller et al., 1989a; Constantine-Paton et al., 1990). In mammals, where the visually driven afferents are initially intermingled in the lateral geniculate nucleus and in the visual cortex, retinal ganglion ccll (RGC) activity is required to segregate the afferent terminal arbors into eye-specific termination zones and to refine response properties of individual visual neurons (Hubel et al., 1977; Dubin et al., 1986; Stryker and Harris, 1986; Shatz and Stryker, 1988). In the visual system of frogs and fish, where the positions of RGC synapses shift as the animals grow, RGC activity is required for the establishment and maintenance of a topographic projection within the developing or regenerating retinotectal system (Meyer, 1983; Schmidt and Edwards, 1983; Reh and Constantine-Paton, 1985; Cook, 1988). The cellular interactions underlying the activity-dependent sorting process are believed to depend on the highly correlated patterns of action potentials known to exist between neighboring RGCs of the same response type (Arnett, 1978; Arnett and Spraker, 1981; Mastronarde, 1983a, b; Ginsberg et al., 1984). In the retinotectal system, where a number of arbors from different RGCs converge on the same tectal neurons, it is thought that a high degree of point-to-point order would arise if coactive synapses of neighboring RGCs were selectively stabilized at the expense of noncoactive synapses from disparately positioned RGCs. However, the mechanisms through which coactivity might be recognized and translated into selective synapse stabilization remain unclcar.

Activation of the NMDA receptor, a type of excitatory amino acid (EAA) receptor, has been proposed as a cellular mechanism underlying the recognition of afferent coactivity, because it con- 
ducts the second messenger calcium only when ligand binding and postsynaptic membrane depolarization occur simultaneously (MacDermott et al., 1986; reviewed in Mayer and Westbrook, 1987a; Cotman et al., 1988). It is thought that the calcium conductance through the NMDA channel initiates the stabilization of the coactive synapses (Cline et al., 1987; Cline and Constantine-Paton, 1989; Constantine-Paton et al., 1990). An increasing number of reports are consistent with this proposal. For instance, EAAs have been shown to be the likely transmitter in the projection neurons in many sensory systems (reviewed in Hicks, 1987), including the geniculocortical projection in cats (Fox et al., 1989; Miller et al., 1989b) and the retinotectal projection in frogs (Debski et al., 1987; Fox and Fraser, 1987; Debski and Constantine-Paton, 1988; McDonald et al., 1989). Complementary receptor binding studies have shown that thalamic and cortical brain regions involved in the transmission of sensory input are rich in glutamate-sensitive binding sites, including the NMDA-sensitive subclass of glutamate binding sites (Greenamyre et al., 1985; Monaghan and Cotman, 1985; McDonald et al., 1989; reviewed by Cotman et al., 1988). Further support is derived from studies in the visual systems of amphibians, fish, and kittens, where chronic treatments with NMDA receptor antagonists alter the structural or functional organization of afferent arbors in the target (Cline et al., 1987; Kleinschmidt 'et al., 1987; Cline and Constantine-Paton, 1989; Scherer and Udin, 1989; Schmidt, 1990). The critical role of the NMDA receptor in a developmental process that ultimately determines neural connections suggests that the receptor may have a role not only in synaptic transmission, but also in the structural modifications in the developing visual system.

The development of refined visual projections includes a restructuring of individual afferent arbors (LeVay et al., 1978; Reh and Constantine-Paton, 1984; Stretavan and Shatz, 1986). Indeed, rearrangements of neuronal architecture in living animals have been documented in several systems (Purves et al., 1986, 1987; Voyvodic, 1987; Sutula et al., 1988; Harris and Purves, 1989; Wigston, 1989). Numerous studies in cell culture implicate EAA neurotransmitters in the regulation of neurite outgrowth and synaptogenesis (see Mattson, 1988, for review), although the particular responses appear to be specific to neuron type and culture conditions. Furthermore, the relative importance of these factors for in vivo regulation of cell structure is poorly understood. We have examined the structural responses of retinal afferent arbors to chronic in vivo application of NMDA receptor antagonists and agonists in an effort to understand the events that occur during the activity-dependent rearrangements of the developing retinotectal projection.

Our experiments capitalize on several properties of the developing Rana pipiens retinotectal pathway. First, as the retina and tectum grow, arbors from the oldest central RGCs may shift their positions by roughly half the tectum's rostrocaudal length (approximately $1 \mathrm{~mm}$ ), in order to maintain the center of the retinal projection in the center of the tectal target field (Gaze et al., 1979; Reh and Constantine-Paton, 1984). Nevertheless, retinotectal synapses are functional during this developmental period. This means that retinotectal synapses have relatively short lifetimes and that the mechanisms that maintain topographic order as these synapses are broken and remade must be continuously active throughout the period of larval growth.

Second, a stereotyped striped pattern of eye-specific afferent terminal segregation can be induced by implanting a supernumerary eye primordium into the forebrain region of early em- bryos. The stripe pattern is superimposed on a normal topographic retinotectal projection and is robust under a variety of experimental manipulations. Afferent segregation occurs whenever RGC terminal arbors from normal and supernumerary eyes attempt to establish synapses in the same region of the tectum. The pattern appears to arise through the combined operation of the activity-independent and activity-dependent mechanisms that are thought to produce the continuous retinotopic projection in normal animals (for review, see Udin and Fawcett, 1988). Namely, cell surface cues are thought to guide arbors to a retinotopically correct region of the tectum. A subsequent activitydependent process is thought to refine the crudely topographic projection by selectively stabilizing arbors from neighboring, coactive RGCs at the same target site.

We report that chronic in vivo treatments with drugs thought to interact specifically with the NMDA receptor result in a significant restructuring of the RGC terminal arbor. Our data are consistent with the model that NMDA receptor activation initiates the stabilization of the coactive synapses. Furthermore, we suggest that NMDA receptor activation influences the growth of afferents by regulating branch initiation and retraction.

\section{Materials and Methods}

Preparation of Elvax. Elvax plastic polymer (Dupont, Inc.) was prepared as described in detail elsewhere (Silberstein and Daniel, 1982). Briefly, the plastic was solubilized in methylene chloride $(100 \mathrm{mg}$ Elvax $/ 1 \mathrm{ml}$ solvent). Concentrated solutions of drugs, prepared in either distilled water or saline, were added to the plastic solution along with Fast green $(0.01 \%$, final concentration). The Elvax was mixed with a vortex, frozen rapidly in a dry ice/acetone bath, and stored for $2 \mathrm{~d}$ to 2 months at $-20^{\circ} \mathrm{C}$. The Elvax was put under gentle vacuum for $1-2 \mathrm{~d}$ and embedded in OCT embedding solution and cut into $30-\mu \mathrm{m}$ slabs on a cryostat for surgical implantation. Constant levels of drugs are released from the Elvax for at least $60 \mathrm{~d}$ (Cline and Constantine-Paton, 1989).

Surgery. All animals were anesthetized by submersion in $0.05 \%$ 3-aminobenzoic acid (MS222; Sigma) prior to any surgical procedures.

Elvax implants. The dorsal surface of the optic tectal lobes of tadpoles (stages X-XVIII, Taylor and Kollros, 1946) and postmetamorphic froglets (1-3 months after metamorphosis) were exposed by reflecting the overlying skin and cartilaginous skull. The dura and arachnoid membranes were opened along the midline and the pia was either lifted away from the tectal lobe in a sheet or peeled away to expose the surface of the tectal neuropil. Elvax pieces were laid over the dorsal tectal surface and pushed around the lateral edge of the lobes. The Elvax was held in place by the pial and/or arachnoid membranes. The brain covering and skin were replaced and the wound was sealed with Histoacryl glue (TriHawk, Montreal). Animals recovered from surgery in oxygenated dilute Instant Ocean (Aquarium Systems) supplemented with Penn/Strep (100 units/liter; Sigma). The position of the Elvax was verified at the end of the experiment. Animals were not used if the Elvax could not be recovered over the tectum.

HRP labeling. To label the entire supernumerary projection the supernumerary optic nerve was cut immediately behind the eye and a small piece of Gelfoam soaked with saturated HRP solution (Sigma, Type VI, or Boehringer Mannheim, Grade 1) was placed at the cut end of the nerve. After $2 \mathrm{~d}$, the animals were killed and the brains were reacted in whole mount with DAB as described previously (Reh and Constantine-Paton, 1984). The tectal lobes were dissected free from the brain, flat-mounted between coverslips, and fixed in either $4 \%$ paraformaldehyde or $2 \%$ paraformaldehyde and $2 \%$ glutaraldehyde in $0.1 \mathrm{M}$ phosphate buffer for $3-4 \mathrm{~d}$ at $4^{\circ} \mathrm{C}$. They were subsequently rinsed in 0.1 M phosphate buffer, dehydrated, cleared in xylene, and mounted in Permount.

To label a smaller population of RGC axons for terminal arbor reconstruction, tungsten needles tipped with HRP crystals were introduced into either the supernumerary retina or the optic nerve near the optic nerve head. The brains were processed as described above. Individual HRP-labeled RGC terminal arbors were drawn with a camera lucida using a $63 \times$ oil immersion lens. Because arbor morphologies differ with position within the tectum, arbors were selected for recon- 

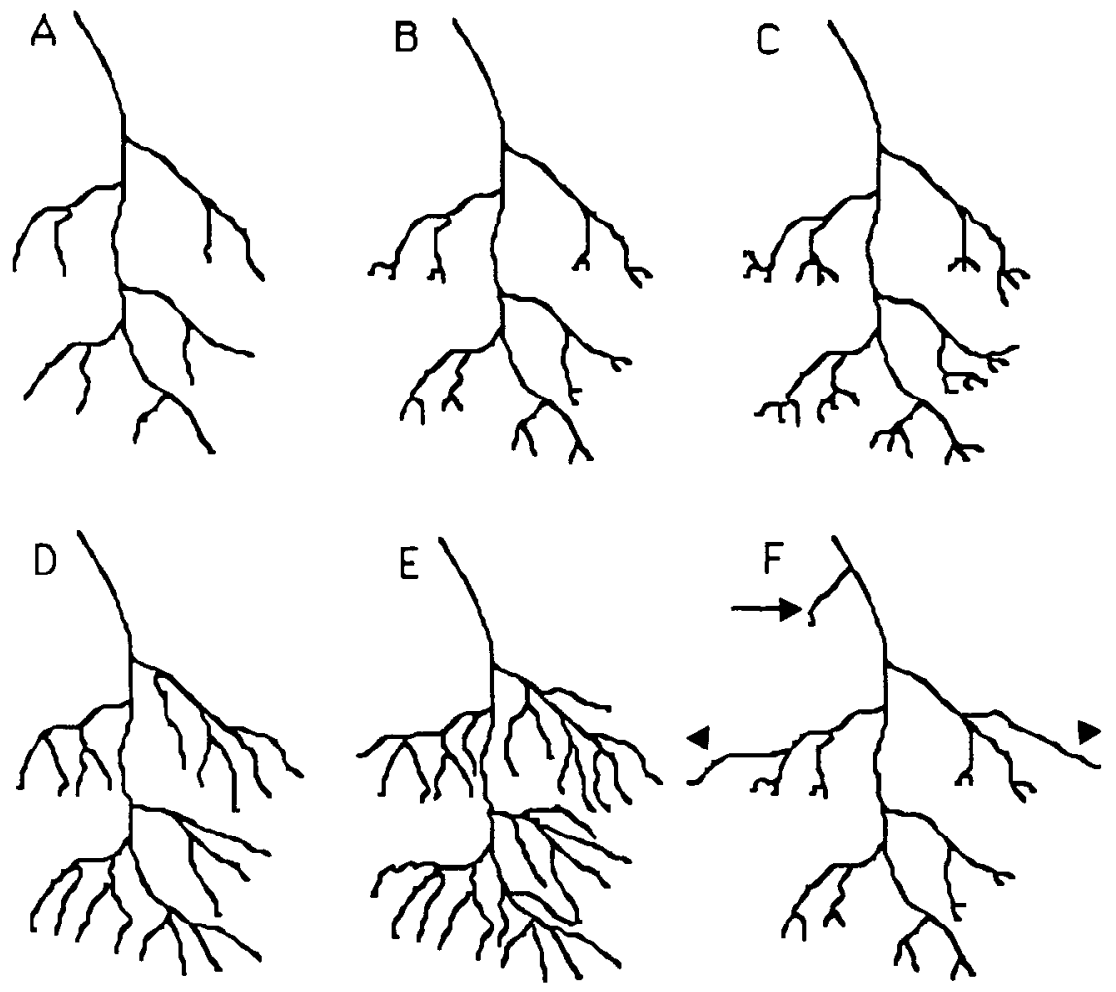

Figure 1. Schematic diagram of differences in arbor morphologies depending on the number and distribution of terminal branch tips. A basic arbor skeleton $(A)$ is modified by the addition of $1(B)$ or $2(C)$ fine terminal branchlets to the end of each branch. These modifications either double $(B)$ or triple $(C)$ branch tip number without a significant increase in arbor area, resulting in an increased arbor density. If the same number of branches are added to the basic arbor, but they are longer and distributed throughout the arbor, as shown in $(D)$ and $(E)$, then measurements of arbor area are greater, and the branch densities of $D$ and $E$ would be less than $B$ and $C$. Notice that area measurements are relatively insensitive to the extension of a simple lateral process $(F$, arrowheads), which would increase the value of width measurements, or the extension of a single branch from the primary axon $(F, a r$ row), which would result in an increased length measurement. struction from the rostromedial quadrant of the tectum. This was also the region of the tectum where it was easiest to verify that the Elvax had remained in contact with the tectum throughout the exposure period. To control for variation in arbor morphology with the stage of the animal, we have drawn arbors from stage-matched untreated or shamoperated control animals. Furthermore, since the different RGC classes which terminate in different laminae of the tectal neuropil exhibit a range in morphologies (Lazar and Szekely, 1969; Potter, 1972), which is particularly noticeable in adult frogs rather than tadpoles, we have confined our samples to arbors drawn from the central regions of lamina 9 , extending into the superficial region of lamina 8 , with the exception of one arbor in the experimental and control groups drawn from the most superficial lamina.

Arbor morphology analysis. We used a digital bitpad and Terak computer to obtain (1) maximal rostrocaudal length taken from the first branch off the parent axon to the furthest tip, (2) maximal width perpendicular to the long axis, and (3) a tangential area obtained by tracing an outline of the terminal closely adjacent to each branch. The branch outlines of camera lucida drawings of approximately $790 \times$ magnification were traced with a mouse. This allowed the area contributed by each branch to be determined except at branch tips where branchlets are close together. Each drawing was traced 3 times and the average value was taken as the tangential area. Typically individual values did not vary from the mean by more than $2 \%$. The tangential area measured from the 2-dimensional drawings is a reasonable estimate of the arbor area because the retinal terminal arbors arc unusually flat (note, for instance, the photograph of the arbor in Fig. 11). However, even these accurate area measurements do not reflect subtle changes of arbor morphology. Therefore, we have also counted the number of branch tips and determined the branch density or the number of branch tips per area, as indicators of the growth or sprouting or branch retraction in the arbors. Figure 1 is a cartoon of several arbor types to illustrate this point. A skeletal arbor morphology $(A)$, with 10 branch tips, is modified in each of the remaining arbors. In the arbor type diagrammed in $B$, the branch number is doubled without significantly increasing arbor area by ending each branch in a short, 2-pronged fork. Similarly, in the arbor type shown in $C$, the branch number is tripled without significantly increasing arbor area by ending each branch in a short, 3-pronged fork. Consequently, branch tip density can be dramatically increased or decreased without a significant change in the tangential area covered by the arbor. In contrast, doubling (as in arbor $D$ ) or tripling (as in arbor
$E$ ) the branch number by adding branches that are relatively long and evenly distributed along the original skeletal arbor increases both branch tip number and tangential area. The area of the arbor is not sensitive to the addition of a branch along the primary axon (arrow in $F$ ), which increases the length of the arbor, or the addition of a branch at the lateral edge of an arbor (arrowhead in $F$ ), which increases the width of the arbor.

Cell counts. Tectal cell density in layer 6 was determined in toluidine blue- or hematoxylin-stained histological sections by counting the number of cell bodies in a $625 \mu \mathrm{m}^{2} \times 10 \mu \mathrm{m}$ volume under $400 \times$ magnification (Constantine-Paton and Ferrari-Eastman, 1987). Retinal ganglion cell density was determined by counting the number of retinal ganglion cell bodies in 4 alternating $10-\mu \mathrm{m}$ sections through the optic nerve head. The length of the RGC layer was measured with a Terak computer and the cell number per length was determined.

Statistical analyses were performing using a 2-tailed Student's $t$ test (Snedecor and Cochran, 1967).

\section{Results}

\section{NMDA receptor antagonists desegregate stripes}

We treated 3-eyed tadpoles with Elvax containing the noncompetitive NMDA channel blocker MK801 at concentrations of either $10^{-3}$ or $10^{-4} \mathrm{M}$ in Elvax for 4 weeks $(n=1$ for each concentration), 10 weeks ( $n=1$ for each concentration), or 14 weeks ( $n=2$ for each concentration). We assayed the effect of the drug treatment on the organization of the RGC arbors by labeling the supernumerary retinal projection with HRP. Although none of these treatments resulted in a complete desegregation of the eye-specific stripes, tecta from tadpoles treated for 14 weeks with MK801 at either concentration have stripes from the supernumerary eye that appeared wider than stripes in untreated tecta (Fig. 2). MK801 is a use-dependent NMDA channel blocker (Wong et al., 1986) and can only gain access to the binding site when the channel is open. Exposure of rat cortical neurons to MK801 in the presence of NMDA increases the MK 801 channel blocking activity, presumably by increasing 

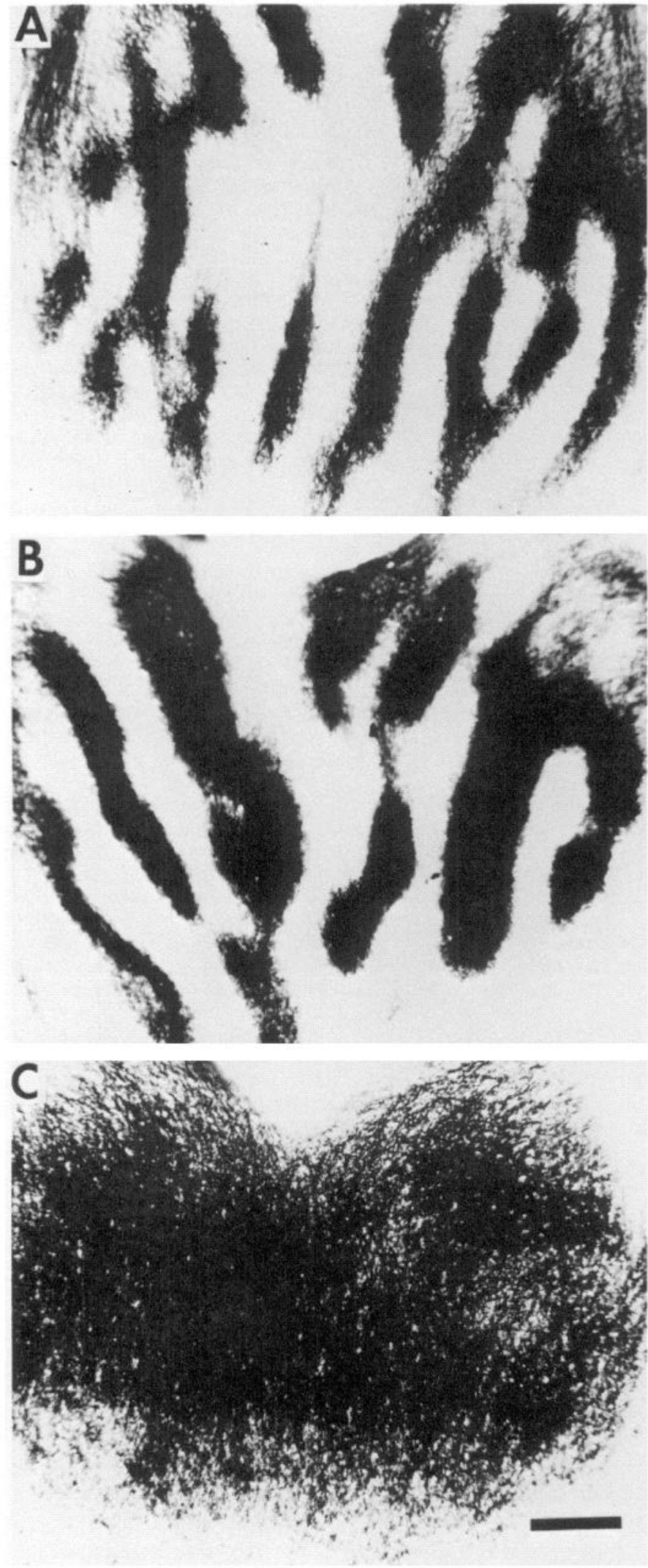

Figure 2. MK801 in combination with NMDA, but not MK801 alone, desegregates eye-specific stripes. $A$, Stripe pattern in an untreated tectum. The central region of the tectum is not striped because the central supernumerary retina projected to the contralateral tectum. $B$, Stripe pattern in a tadpole tectum after 14 weeks of exposure to MK801. C, the probability of NMDA channel opening and therefore of access of the drug to its binding site (Huettner and Bean, 1988). Therefore, we treated 3-eyed tadpoles with combinations of MK801 and NMDA. Treatment with MK801 at $10^{-3} \mathrm{M}$ and NMDA at $10^{-3} \mathrm{M}$ in Elvax for 10 weeks caused stripe desegregation $(n=2)$ (Fig. 2). The MK801/NMDA-induced desegregation is quite sensitive to the concentration of NMDA, since exposure to MK801 at $10^{-3} \mathrm{M}$ and NMDA at $10^{-4} \mathrm{M}$ in Elvax did not cause desegregation in 2 animals tested.

\section{NMDA treatment sharpens stripe borders}

We treated 3-eyed tadpoles with Elvax containing $10^{-2} \mathrm{M}, 10^{-4}$ M, or $10^{-6}$ M NMDA ( $n=6$ for each concentration) for 4 weeks and labeled the supernumerary retinal projection with HRP. Following exposure to $10^{-4} \mathrm{M}$ NMDA in Elvax, the HRP-labeled stripes appear straighter and the stripe boundaries appear sharper than in untreated animals even when viewed at low magnification in the whole-mount brain or in flat-mounted tecta (Fig. 3). Exposure to higher concentrations $\left(10^{-2} \mathrm{M}\right.$ in Elvax) causes beading and blebbing in the RGC arbors. Exposure to low concentrations of NMDA $\left(10^{-6} \mathrm{M}\right.$ in Elvax) does not change the stripe pattern.

To test the specificity of the response to NMDA, the tecta of 3-eyed tadpoles were exposed to glutamate over a concentration range of $10^{-6}$ to $10^{-2} \mathrm{M}$ in Elvax ( $n=3$ for each concentration). Glutamate, which is expected to activate both the NMDA and non-NMDA receptor types, does not alter the stripe pattern at any concentration used (Fig. 4). HRP-labeled arbors from glutamate-treated tecta are not beaded or blebbed, nor do they express any other obvious signs of toxicity. The lack of a morphological response to glutamate may be due to high-affinity uptake systems in glia and neurons, which would reduce the concentration of glutamate reaching the tectal cell synapses.

We quantified the degree of sharpness of stripe borders induced by NMDA treatment by counting the number of axons that cross from the stripe to the interstripe zone (Fig. 3, righthand panel). A line on an eyepiece grid was placed on a stripe border and all axons seen at $160 \times$ magnification crossing the line and traversing at least $50 \%$ into the interstripe zone were counted. Comparable border lengths were examined in NMDAtreated and untreated animals. Untreated animals have $12.5 \pm$ 0.7 axons $/ 550 \mu \mathrm{m}$ crossing from a stripe to interstripe zone ( $n$ = 12 stripe boundaries, 4 tadpoles), whereas NMDA-treated animals have $4.2 \pm 0.5 \mathrm{axons} / 550 \mu \mathrm{m}$ crossing from a stripe to interstripe zone ( $n=12$ stripe boundaries, 4 tadpoles). This dramatic $75 \%$ decrease in the number of axons crossing stripe borders may account for the appearance of the sharp borders seen at lower magnifications.

\section{Drug treatment alters RGC terminal morphology}

To investigate further the role of the NMDA receptor in the retinotectal projection, we conducted a detailed analysis of the morphology of individual RGC arbors in untreated, APV-, and NMDA-treated 3-eyed tadpoles. However, we noticed that even without drug treatment, considerable differences existed between RGC arbor morphology in singly innervated tecta from 2 -eyed animals compared to doubly innervated tecta from 3 -eyed

Desegregated pattern after 10 weeks of exposure to MK801 and NMDA in the same piece of Elvax. Scale bar, $200 \mu \mathrm{m}$. 
Table 1. Characteristics of RGC terminal arbors from 3-eyed tadpoles

\begin{tabular}{llllll} 
Treatment & Length $(\mu \mathrm{m})$ & Width $(\mu \mathrm{m})$ & Area $\left(10^{3} \mu \mathrm{m}^{2}\right)$ & Branch no. & $\begin{array}{l}\text { Branch } \\
\text { no./area } \\
\left(n / 10^{3} \mu \mathrm{m}^{2}\right)\end{array}$ \\
\hline Untreated $(n=12)$ & $540 \pm 43$ & $230 \pm 28$ & $31.3 \pm 4.3$ & $169 \pm 24$ & $5.6 \pm 0.6$ \\
DL-APV $(n=11)$ & $410 \pm 62^{a}$ & $190 \pm 21^{b}$ & $26.1 \pm 5.2$ & $76 \pm 10^{a}$ & $3.6 \pm 0.8^{a}$ \\
NMDA $(n=10)$ & $406 \pm 38^{a}$ & $215 \pm 22$ & $25.3 \pm 6.5$ & $60 \pm 9^{a}$ & $2.7 \pm 0.2^{a}$
\end{tabular}

${ }^{a} p<0.001$.

${ }^{n} p<0.005$.

animals, and that these differences might be relevant to drug effects on morphology in 3-eyed animals. Analysis of the terminal arbor morphology in 2-eyed tadpoles has been reported elsewhere (Cline and Constantine-Paton, 1989).

\section{Tadpole arbors}

Untreated arbors. Twelve arbors were drawn from the rostromedial tectum of 3 untreated and 3 sham-operated 3-eyed tadpoles (Fig. 5, top row; Fig. 6; Table 1). No differences were seen between the arbors from the 2 groups and they were pooled to one control group. RGC arbors terminating in the rostromedial tectum of 3-eyed tadpoles usually enter the rostral tectum from the medial optic tract. Short, relatively unbranched processes occasionally extend from the major axon rostral to the terminal arbor. The sparse rostral processes often terminate in blunt endings and no growth cones were seen. The terminal arborization is a dense profusion of branches restricted to the distal 450-700 $\mu \mathrm{m}$ of the axon (mean arbor length is $540 \pm 43 \mu \mathrm{m}$, range $=$ $290-700 \mu \mathrm{m})$. The arbors typically extend about $150-250 \mu \mathrm{m}$ mediolaterally (mean arbor width is $230 \pm 28 \mu \mathrm{m}$, range $=130-$ 460 ), although 2 of the 12 arbors were between 300 and 400 $\mu \mathrm{m}$ wide. The terminal arbors cover a tangential area of 31.3 $\pm 4.3 \times 10^{3} \mu \mathrm{m}^{2}$, range $=16.8-38.3 \times 10^{3} \mu \mathrm{m}^{2}$. Two particularly revealing features of the arbors in terms of arbor growth patterns and drug response are the number of branch endings and the branch density, or branch number per area. The mean branch number in untreated arbors from doubly innervated tecta is 169 \pm 24 branches per arbor (range $=52-225$ ), about twice the branch number in arbors from untreated singly innervated tecta (Cline and Constantine-Paton, 1989). The branch density is 5.6 \pm 0.6 branches $/ 10^{3} \mu \mathrm{m}^{2}$ (range $=2.5-10.1$ branches $/ 10^{3} \mu \mathrm{m}^{2}$ ), also approximately twicc the valuc for arbors from 2-cycd tadpoles. The increase in branch tip number and in branch density in arbors from the 2- and 3-eyed tadpoles is due primarily to an increase in the number of forked branch endings in arbors from 3-eyed tadpoles, comparable to the differences between arbors $B$ and $C$ in Figure 1. Although growth cones are not well preserved in paraformaldehyde-fixed tissue, the arbors drawn from tecta fixed in a glutaraldehyde/paraformaldehyde mixture are rich in growth cones throughout the central and distal regions of the arbor.

$A P V$-treated arbors. We have previously reported that APV treatment does not alter the tangential area covered by the arbors drawn from 2- or 3-eyed tadpoles (Cline et al., 1987; Cline and Constantine-Paton, 1989). This more detailed examination of terminal arbors from 3-eyed APV-treated tadpoles revealed some differences between APV-treated and untreated arbors (Fig. 5, middle row; Fig. 6; Table 1). Eleven arbors were drawn from 6 APV-treated 3-eyed tadpoles. APV-treated arbors are shorter (mean length is $410 \pm 62 \mu \mathrm{m}$ for APV-treated arbors, range $=$ 170-700, compared to $540 \pm 43 \mu \mathrm{m}$, range $=290-700 \mu \mathrm{m}$, for untreated arbors, $p<0.001)$ and narrower $(190 \pm 21 \mu \mathrm{m}$, range $=85-300$ for APV-treated arbors compared to $230 \pm 28 \mu \mathrm{m}$, range $=130-460$ for untreated arbors, $p<0.005$ ). The histograms (Fig. 6) demonstrate that the differences in mean length and width represent a genuine shift in the population of the arbors, rather than the inclusion of a single aberrant arbor in an otherwise unchanged group of arbors. The tangential areas of APV-treated arbors are not significantly different from those of untreated arbors. APV treatment reduces the number of terminal branches per arbor ( $76 \pm 10$ branches/arbor, range $=29-$ 145 for APV-treated arbors, compared to $169 \pm 24$ branches/ arbor for untreated arbors, $p<0.001)$. This is also expressed as a $35 \%$ decrease in branch density in APV-treated arbors $(3.6$ \pm 0.8 branch endings $/ 10^{3} \mu \mathrm{m}^{2}$, range $=1.1-10.5$ branches $/ 10^{3}$ $\mu \mathrm{m}^{2}$, compared to $5.6 \pm 0.6$ branch endings $/ 10^{3} \mu \mathrm{m}^{2}, p<0.001$ ).

NMDA-treated arbors. Ten arbors were drawn from 6 NMDAtreated 3-eyed tadpoles (Fig. 5, bottom row; Fig. 6; Table 1). Terminal arbors from NMDA-treated 3-eyed tadpoles are significantly shorter than those from untreated arbors $(406 \pm 62$ $\mu \mathrm{m}$ for NMDA-treated arbors, range $=230-600$, compared to $540 \pm 43 \mu \mathrm{m}$, range $=290-700 \mu \mathrm{m}$, for untreated arbors, $p<$ 0.001 ), but do not differ significantly from APV-treated arbors. NMDA-treated arbors are not significantly different from untreated arbors with respect to their width $(215 \pm 22 \mu \mathrm{m}$ for NMDA-treated arbors, range $=110-300$, compared to $230 \pm$ $28 \mu \mathrm{m}$, range $=130-400$ for untreated arbors) or tangential area (26.1 $\pm 5.2 \times 10^{3} \mu \mathrm{m}^{2}$ for NMDA-treated arbors compared to $31.3 \pm 4.3 \times 10^{3} \mu \mathrm{m}^{2}$ for control arbors).

Arbors from NMDA-treated tecta are less elaborate in their branching pattern compared to untreated or APV-treated arbors (Fig. 5, bottom row). They have fewer branch points and fewer branch endings than control arbors $(60 \pm 9$ branch endings for NMDA-treated arbors, range $=29-112$ compared to $169 \pm 24$ branch endings/arbor for controls, $p<0.001$ ). Branches from untreated animals often end in a spray of several fine branches, whereas most branches of NMDA-treated arbors terminate as a single branch tip. Nevertheless, HRP does label growth cones, indicating that complete HRP labeling does occur in NMDAtreated arbors, and that growth cone formation occurs in the presence of NMDA. The mean branch density for NMDAtreated arbors is $2.7 \pm 0.2$ branch endings $/ 10^{3} \mu \mathrm{m}^{2}$ (range $=$ 1.4-3.9 branches $/ 10^{3} \mu \mathrm{m}^{2}$ ), compared to a mean branch density of $5.6 \pm 0.6$ branch endings $/ 10^{3} \mu \mathrm{m}^{2}$ for untreated arbors (range $=2.5-10.1$ branches $/ 10^{3} \mu \mathrm{m}^{2} ; p<0.001$ ). This represents a $52 \%$ decrease in branch density. They have a uniformly low branch density revealed by the histogram (Fig. 6). NMDA-treated arbors also have a significantly lower branch density than APV- 

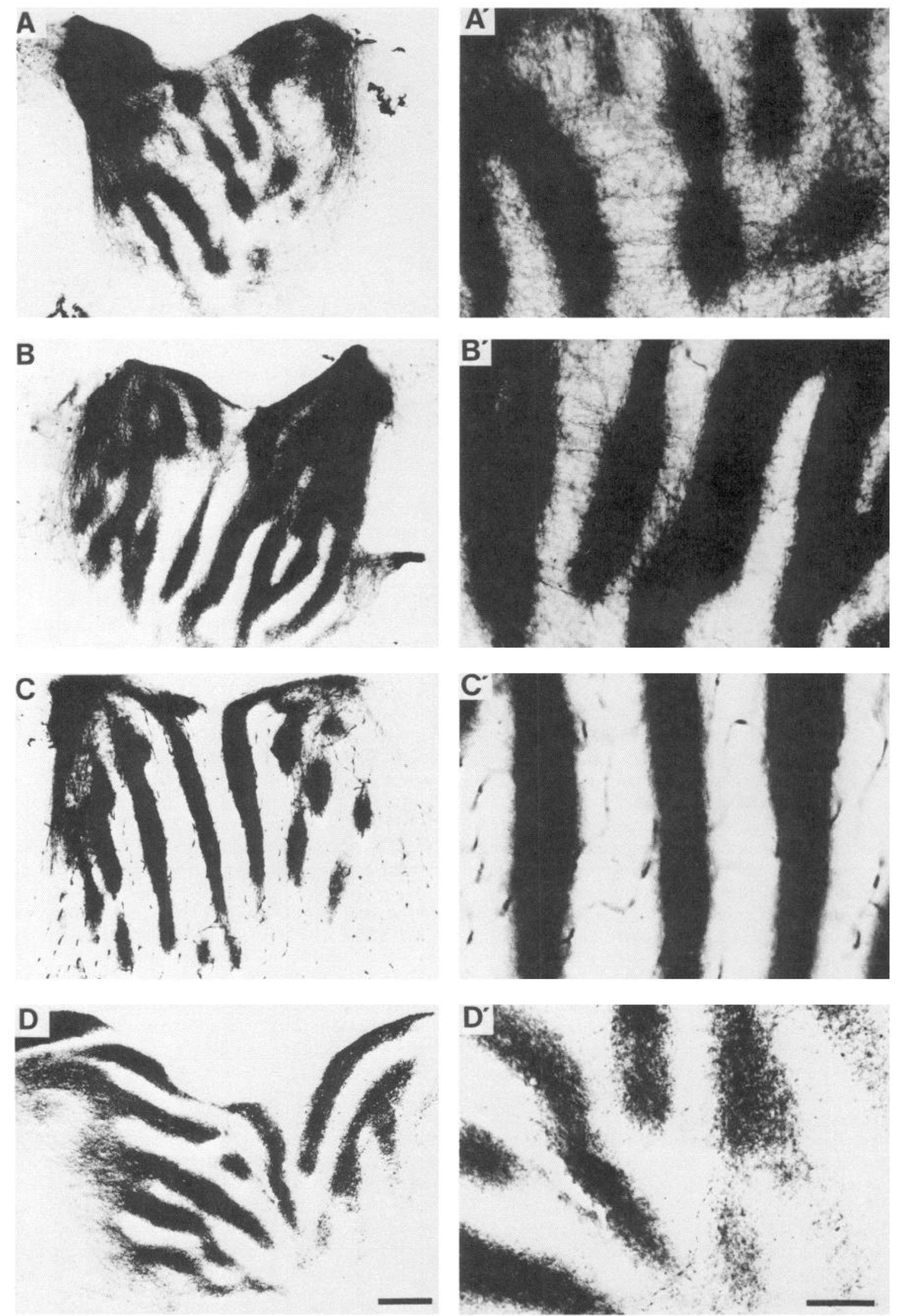

Figure 3. Concentration dependence of NMDA-induced stripe sharpening. Elvax prepared with saline $\left(A, A^{\prime}\right)$, NMDA $10^{-6}$ M $\left(B, B^{\prime}\right)$, NMDA $10^{-4} \mathrm{M}\left(C, C^{\prime}\right)$, or NMDA $10^{-2} \mathrm{M}\left(D, D^{\prime}\right)$ was implanted subpially over the tectal lobes of 3-eyed tadpoles. After 4-6 weeks the supernumerary projection was visualized with HRP. The photographs on the left are flat-mounted tecta, and on the right are closeups of a portion of the tectum 
treated arbors $\left(2.7 \pm 0.2\right.$ branch endings $/ 10^{3} \mu \mathrm{m}^{2}$ for NMDAtreated arbors compared to $3.8 \pm 0.8$ branch endings $/ 10^{3} \mu \mathrm{m}^{2}$ for APV-treated arbors, $p<0.001$ ). The absence of fine terminal branchlets accounts for a major portion of the decreased arbor density.

The importance of multiple measures of arbor morphology (see Methods and Fig. 1) is apparent in the summary of these data presented in Table 1. For example the mean length and width of untreated tadpoles is significantly greater than the mean length and width of treated arbors. However, the tangential area measurements indicate that the actual tectal area covered by these arbor types is not different. Comparison of arbors from untreated 2-eyed and untreated 3-eyed tadpoles reveals an example of the value of the data on branch tip number and branch density. Both of these arbor types have the same tangential area, but the branch densities of arbors from 3-eyed tadpoles are greater than the branch densities of 2-eyed tadpoles because the addition of fine terminal branchlets increases the total branch tip number without significantly increasing the tangential area. This is similar to the comparison between arbor $A$ and arbor $C$ in Figure 1.

\section{Postmetamorphic frog arbors}

The morphology of RGC arbors drawn from untreated 3-eyed postmetamorphic frogs differs from that of 3-eyed tadpoles. Since the parameters of tangential area, length, width, and branch density change significantly after metamorphosis, we asked whether exposure of the optic tectum of young frogs to NMDA produced the same kinds of alterations in stripe pattern and arbor morphology as seen in tadpoles. All of the differences observed in NMDA-treated arbors from 3-eyed tadpoles were also seen in the arbors of 3-eyed froglets (Figs. 7, 8, and 9).

Untreated arbors. Seven arbors (postmet arbors) were drawn from 5 frogs between 1 and 3 months postmetamorphosis (Fig. 8, top row; Fig. 9; Table 2). Postmet arbors were smaller than tadpole arbors in length $(290 \pm 60 \mu \mathrm{m}$, range $=100-480)$, width $(130 \pm 15 \mu \mathrm{m}$, range $=90-160)$, and tangential area $(15.8 \pm$ $4.0 \times 10^{3} \mu \mathrm{m}^{2}$, range $\left.=5.4-32.5\right)$. The postmet arbors were more elaborate and densely branched than tadpole arbors. The branch tip number was $164 \pm 27$ (range $=85-266$ ), comparable to values from tadpoles. However, because of the smaller areas, the branch densities of postmet arbors were approximately twice that of tadpole arbors $\left(12.5 \pm 2.3\right.$ branches $/ 10^{3} \mu \mathrm{m}^{2}$, range $=$ 7.4-22.2 branches $/ 10^{3} \mu \mathrm{m}^{2}$ ).

The arbors from postmetamorphic frogs display a range of sizes and branch patterns and can be distinguished into morphological classes based on the tectal neuropil lamina in which they terminate, their branching pattern, and the arbor size. In the deepest layer of the superficial neuropil, arbors with a large tangential area and relatively sparse branching predominate. No arbors of this type were included in the present analysis. In a slightly more superficial layer, the arbors cover an intermediate tangential area and have fine-caliber branches which are densely arborized. Some arbors of this type displayed slight swellings along the branch, as described in some types of arbors from
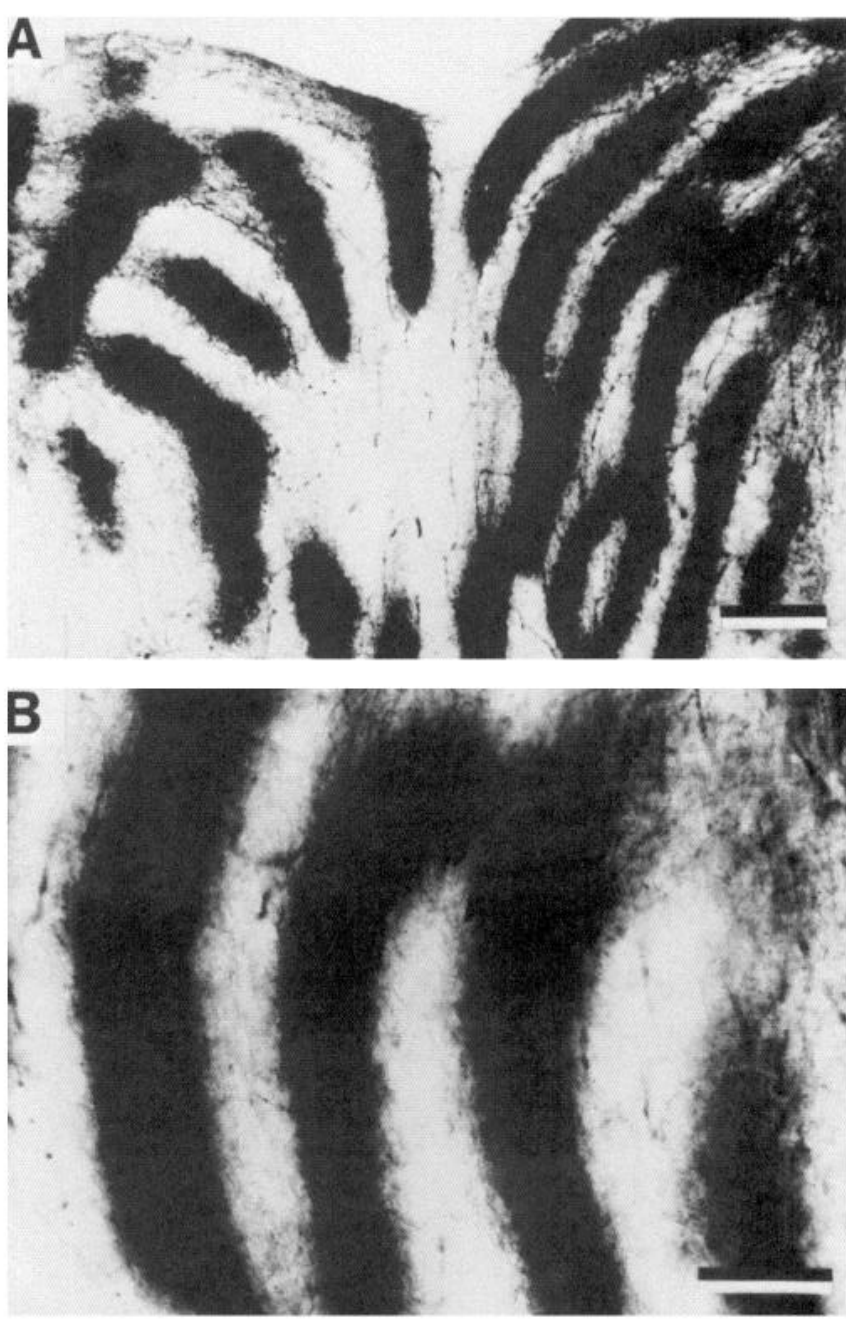

Figure 4. Exposure of the tectum to glutamate $10^{-4} \mathrm{M}$ does not alter the stripe pattern. Tissue preparation and conventions as in Figure 1. Scale bar, $200 \mu \mathrm{m}$ in $A$ and $100 \mu \mathrm{m}$ in $B$.

adult frogs (Stirling and Merrill, 1987); however, this was not a consistent feature of the arbors. It is possible that the swellings, which are thought to represent synaptic sites, develop during the first few months after metamorphosis, and only the older animals examined had developed the swellings. Arbors in the most superficial layer are small and densely branched. One arbor of this type was drawn for each treatment and is shown at the extreme right in Figure 8.

NMDA treatment. We treated 11 postmetamorphic frogs with NMDA $\left(10^{-4} \mathrm{M}\right.$ in Elvax) for 4 weeks and HRP-labeled either the entire supernumerary projection (in 6 animals) or individual RGCs for terminal morphology analysis (in 5 animals). NMDA treatment of the optic tecta of young frogs produces a stripesharpening response comparable to that seen in tadpoles (Fig. 7). Fewer HRP-labeled axons cross from stripe to interstripe

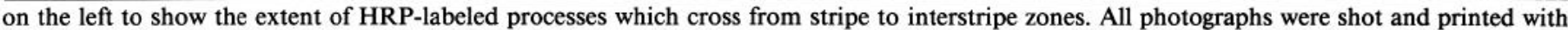

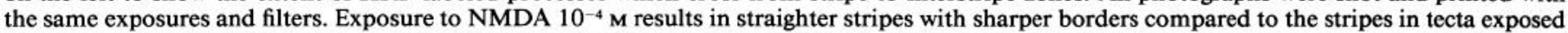

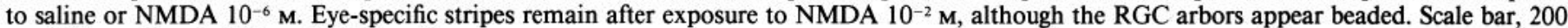
$\mu \mathrm{m}$ (left panel) and $100 \mu \mathrm{m}$ (right panel). 

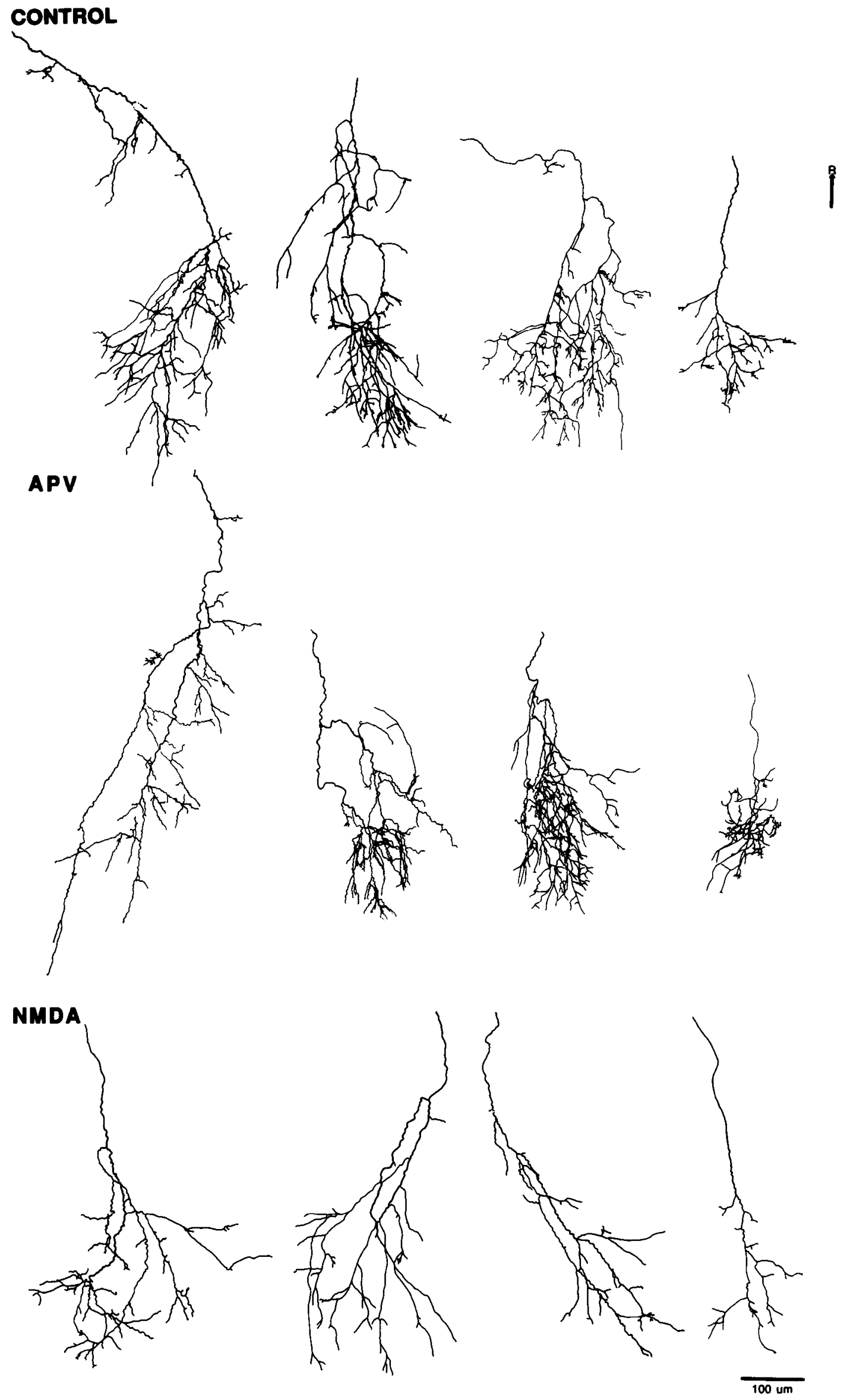

Figure 5. RGC terminal arbors drawn form the rostromedial region of untreated, APV-treated, and NMDA-treated tadpole tecta. Arbors in each vertical column are matched roughly for size and arbor type. Rostral is up, as indicated by the arrow. Scale bar, $100 \mu \mathrm{m}$. 
A

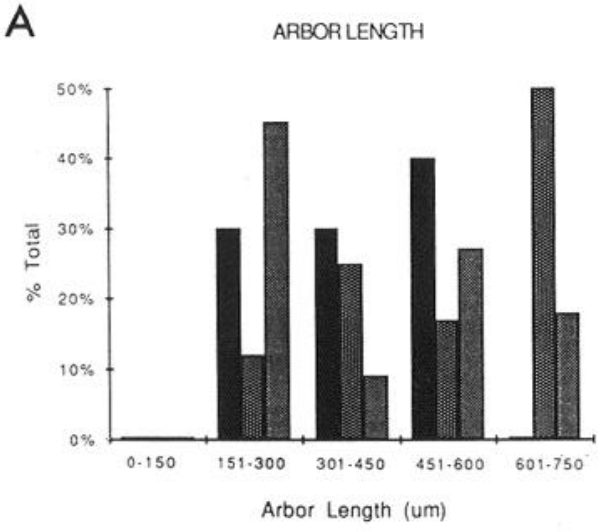

C

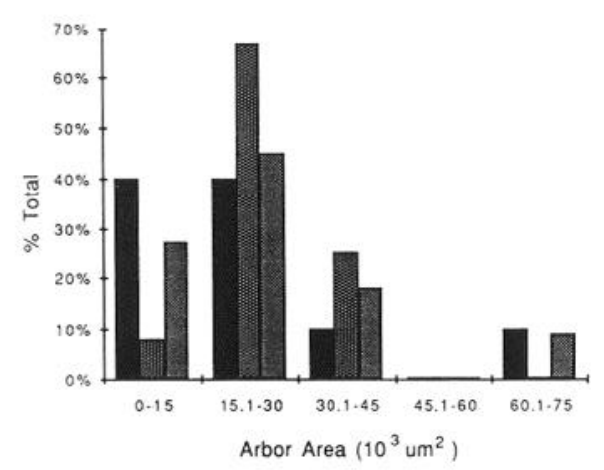

E

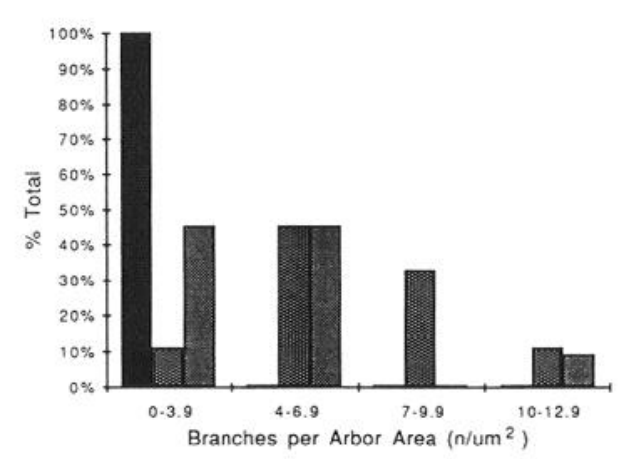

B

ARBOR WIDTH

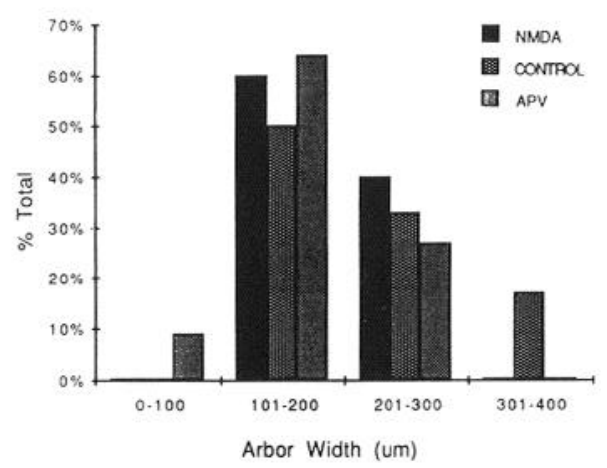

D NUMBER OF BRANCHES PER ARBOR

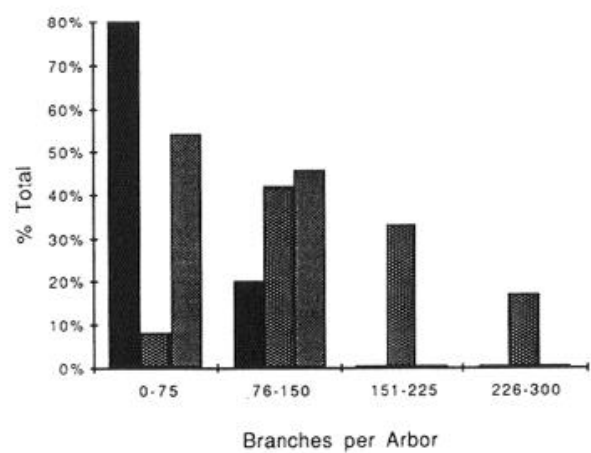

Figure 6. Histograms of the arbor length $(A)$, width $(B)$, tangential area $(C)$, number of branches per arbor $(D)$, and branch density $(E)$ for the arbors drawn from untreated, APV-treated, and NMDA-treated tadpoles. The axis is given as $\%$ total arbors of each treatment to compensate for different sample sizes. Twelve untreated arbors were drawn from 6 tadpoles; 11 APV-treated arbors were drawn from 6 tadpoles; 10 NMDA-treated arbors were drawn from 7 tadpoles. zone, and those which do cross appear to follow a straighter trajectory than axons in untreated tecta. Reconstructions of individual RGC terminal arbors from postmetamorphic frogs revealed that NMDA treatment produced the same types of alterations in arbor morphology as were seen in tadpole arbors. The NMDA-induced decrease in arbor density was even more pronounced in froglets than in tadpoles. Individual HRP-filled terminal arbors from NMDA-treated frogs were compared to terminal arbors drawn from untreated animals of the same age with respect to their tangential area, length, width, number of branch endings, and branch density (Figs. 8 and 9; Table 2). As seen in tadpole arbors, NMDA-treated postmet arbors appear scrawnier than untreated arbors. Although growth cones could be seen, most terminal branches were simple, without forks as commonly seen at the branch tips of untreated arbors. Terminal arbors from NMDA-treated animals do not differ significantly from controls in their lengths $(270 \pm 43 \mu \mathrm{m}$ for NMDA-treated compared to $290 \pm 60 \mu \mathrm{m}$ for controls) or widths $(115 \pm 10$ $\mu \mathrm{m}$ for NMDA-treated compared to $130 \pm 15 \mu \mathrm{m}$ for controls). However, NMDA-treated arbors are somewhat smaller than untreated arbors $\left(11.5 \pm 1.7 \times 10^{3} \mu \mathrm{m}^{2}\right.$ for NMDA-treated arbors, range $=6.0-25.4$, compared to $15.8 \pm 4 \times 10^{3} \mu \mathrm{m}^{2}$ for control arbors, $p<0.005)$. NMDA-treated arbors have dramatically fewer branch endings than control arbors (56 branch endings for NMDA-treated arbors compared to 164 branch endings for control arbors). Branch density in NMDA-treated postmet arbors is reduced by $55 \%$ compared to controls, from 12.5 \pm 2.3 branches $/ 10^{3} \mu \mathrm{m}^{2}$ in control arbors to $5.5 \pm 0.7$ branches/ $10^{3} \mu \mathrm{m}^{2}$ in NMDA-treated arbors.

\section{Toxicity}

NMDA, in the concentrations that result in sharper stripe borders and decreased branch density, does not appear to be toxic to either the retina or the optic tectum. Sections from the tectum 

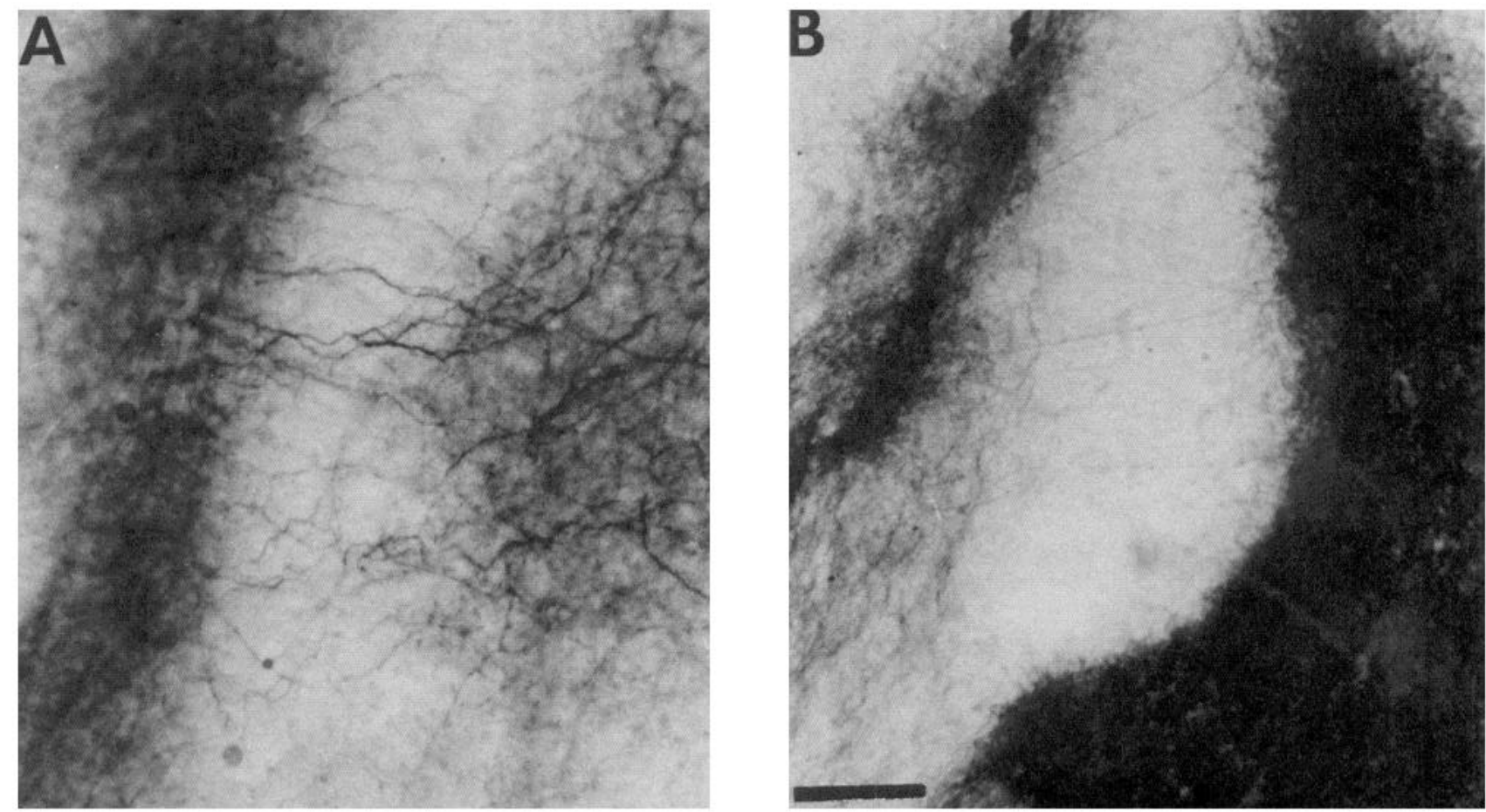

Figure 7. Postmetamorphic frogs exhibit the same sensitivity to NMDA as tadpoles. A, Photograph from an untreated frog tectum in which the supernumerary projection was labeled with HRP. $B$, Photograph from an NMDA-treated frog tectum. Treatment with NMDA $10^{-4} \mathrm{M}$ sharpens the stripe borders and decreases the number of axons crossing from a stripe to an interstripe zone. It appears that the processes that do cross interstripe zones are smaller caliber and follow a straighter path than the axons that cross interstripe zones in untreated postmet tecta. Scale bar, $50 \mu \mathrm{m}$.

and retina from untreated and NMDA-treated postmetamorphic frogs are shown in Figure 10. Neuropil volume is reduced in NMDA-treated tecta, as expected, since the retinal arbors, which constitute the major portion of processes in the superficial neuropil, are more sparsely arborized than in untreated controls. As reported previously in tadpoles (Cline et al., 1987), tectal cell density in layer 6 is not significantly different in NMDAtreated and control postmetamorphic frogs $(17.1 \pm 1.2$ cells/ $6250 \mu \mathrm{m}^{3}$ for NMDA-treated and $18.3 \pm 0.8$ cells $/ 6250 \mu \mathrm{m}^{3}$ for controls). Similarly, retinal ganglion cell density does not differ between untreated and NMDA-treated animals (27.2 \pm $0.8 \mathrm{RGCs} / 100 \mu \mathrm{m}$ from retinae of untreated postmetamorphic frogs compared to $28.2 \pm 1.6 \mathrm{RGCs} / 100 \mu \mathrm{m}$ from retinae of NMDA-treated frogs).

RGC arbors in tecta exposed to NMDA at concentrations that result in sharper stripe borders do not display signs of toxicity. Figure $11 A$ shows a photograph of $3 \mathrm{HRP}$-labeled arbors in an NMDA-treated tectum. These arbors were also drawn with a camera lucida and display the decreased branching density characteristic of NMDA-treated arbors. Notice that the ar- bors are not beaded or necrotic. Following 4 weeks of exposure to higher concentrations of NMDA $\left(10^{-2} \mathrm{M}\right.$ in the Elvax $)$ HRPlabeled retinal arbors appear severely beaded along the entire length of the branches (Fig. 11B). Nevertheless, the higher concentrations of NMDA do not decrease retinal or tectal cell density.

\section{Discussion}

We have exposed the optic tectum of 3-eyed tadpoles and frogs to micromolar concentrations of drugs which are thought to interact specifically with the NMDA receptor and examined both the overall pattern of afferent terminal segregation and the morphology of individual arbors after drug treatments. Eyespecific stripes are present when drugs are introduced and restructuring occurs during the period of drug exposure. The results we present here extend our previous work on the role of the NMDA receptor in the organization of coactive inputs, by suggesting several specific relationships between NMDA receptor activation and terminal arbor morphology.

Table 2. Characteristics of RGC terminal arbors from 3-eyed postmetamorphic frogs

\begin{tabular}{lllllc} 
Treatment & Length $(\mu \mathrm{m})$ & Width $(\mu \mathrm{m})$ & Area $\left(10^{3} \mu \mathrm{m}^{2}\right)$ & Branch no. & $\begin{array}{l}\text { Branch } \\
\text { no./area } \\
\left(n / 10^{3} \mu \mathrm{m}^{2}\right)\end{array}$ \\
\hline Untreated $(n=7)$ & $290 \pm 60$ & $130 \pm 15$ & $15.8 \pm 4.0$ & $164 \pm 27$ & $12.5 \pm 2.3$ \\
NMDA $(n=12)$ & $270 \pm 43$ & $115 \pm 10$ & $11.5 \pm 1.7$ & $56 \pm 6^{a}$ & $5.5 \pm 0.7^{a}$ \\
\hline${ }^{a} p<0.001$.
\end{tabular}



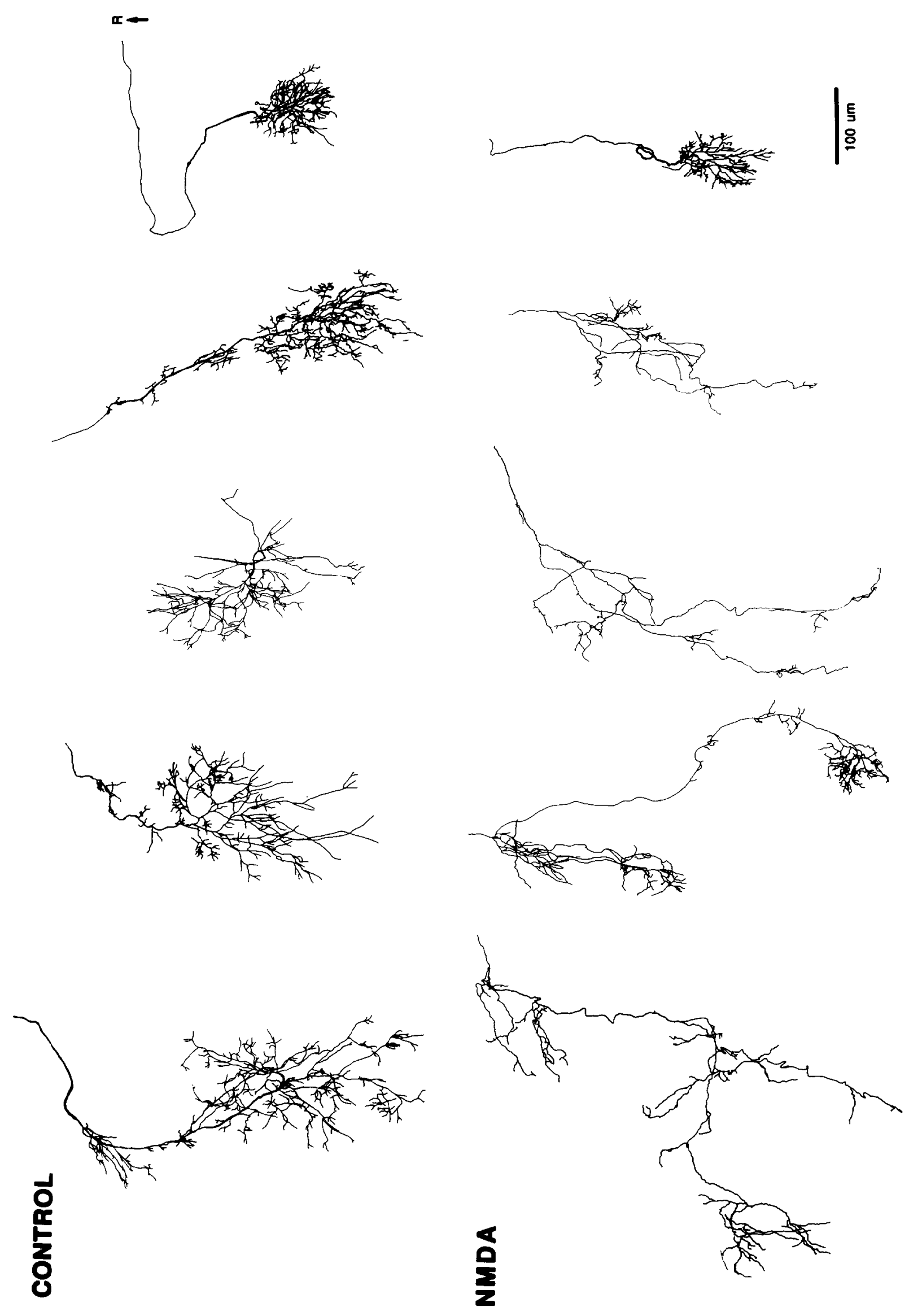

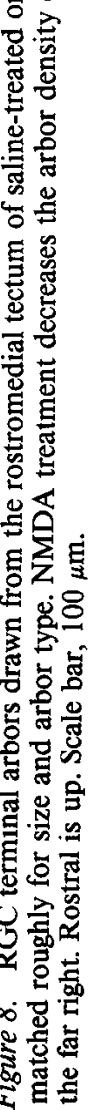


A

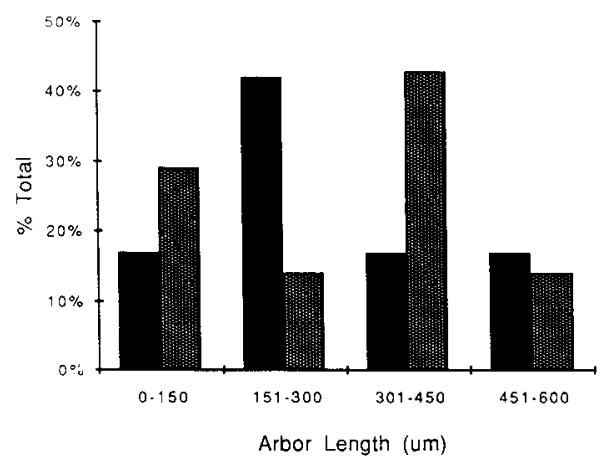

C

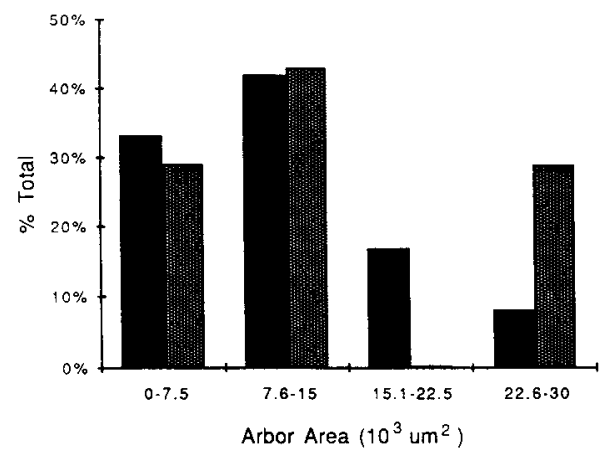

E

Figure 9. Histograms of the arbor length $(A)$, width $(B)$, tangential area (C), number of branches per arbor $(D)$, and branch density $(E)$ for the arbors drawn from untreated and NMDAtreated froglets. Conventions as in Figure 6. Seven untreated arbors were drawn from 3 frogs; 12 NMDA-treated arbors were drawn from 5 frogs.

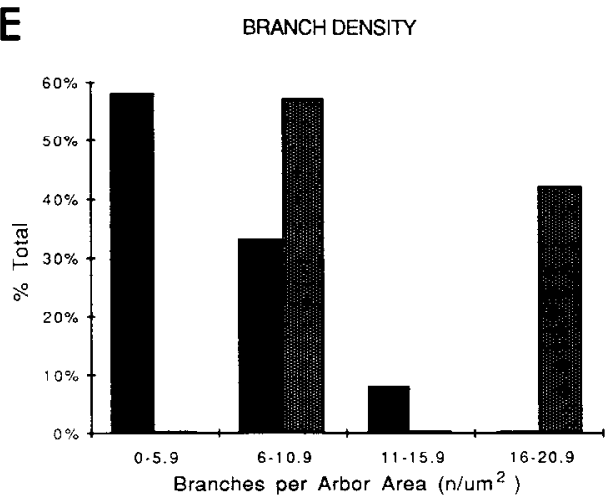

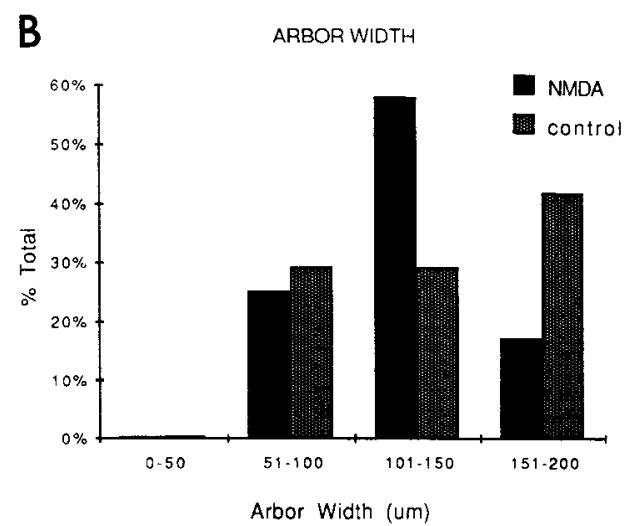

D NUMBER OF BRANCHES PER ARBOR

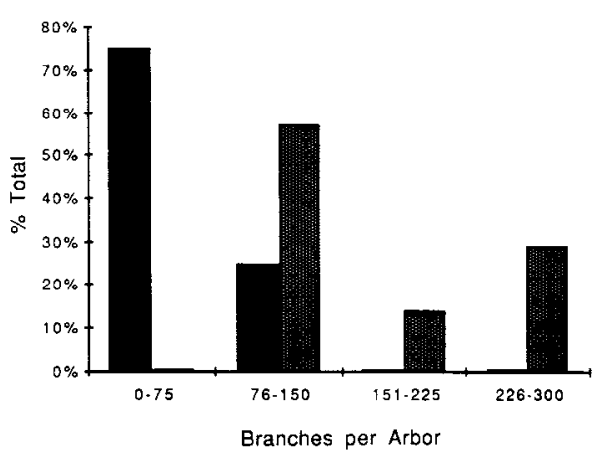

\section{Stripe desegregation by NMDA receptor antagonists}

We have previously shown that exposure of the tecta of 3-eyed tadpoles to the competitive NMDA receptor antagonist APV results in a desegregation of the eye-specific termination zones in the tectum. Here, we show that treatment with the noncompetitive NMDA channel blocker MK801, which is thought to interact with a binding site inside of the NMDA channel, can also desegregate eye-specific stripes when coexposed with the agonist NMDA. Electrophysiological experiments on rat cortical neurons have demonstrated that exposure of the neurons to MK801 in the presence of NMDA increases the ability of MK801 to block the NMDA conductance (Huettner and Bean, 1988). An analogous cooperation between the NMDA and MK801 appears to operate in the retinotectal system. The ability of MK801 to cause stripe desegregation only in the presence of NMDA suggests that MK801 may have limited access to its binding site in untreated animals, as has been observed in other studies using in vivo MK801 administration (Davies et al., 1988). NMDA may facilitate the access of the drug to its binding site

Figure 10. NMDA treatment does not alter retinal or tectal cell density. Hematoxylin-stained sections of tectum from untreated $(A)$ and NMDAtreated $\left(10^{-4} \mathrm{M}\right.$ in Elvax $(B)$ and of retina from untreated $(C)$ and NMDA-treated $\left(10^{-4} \mathrm{M}\right.$ in Elvax) $(D)$ postmetamorphic froglets. The tectal laminae are numbered. In the retina, the ganglion cell layer $(G C L)$, inner nuclear layer $(I N L)$, and outer nuclear layer $(O N L)$ are labeled. The supcrficial ncuropil layers of NMDA-trcatcd animals arc compressed compared to untreated tecta, as might be cxpected if the afferent terminal arbors are less elaborately arborized. 


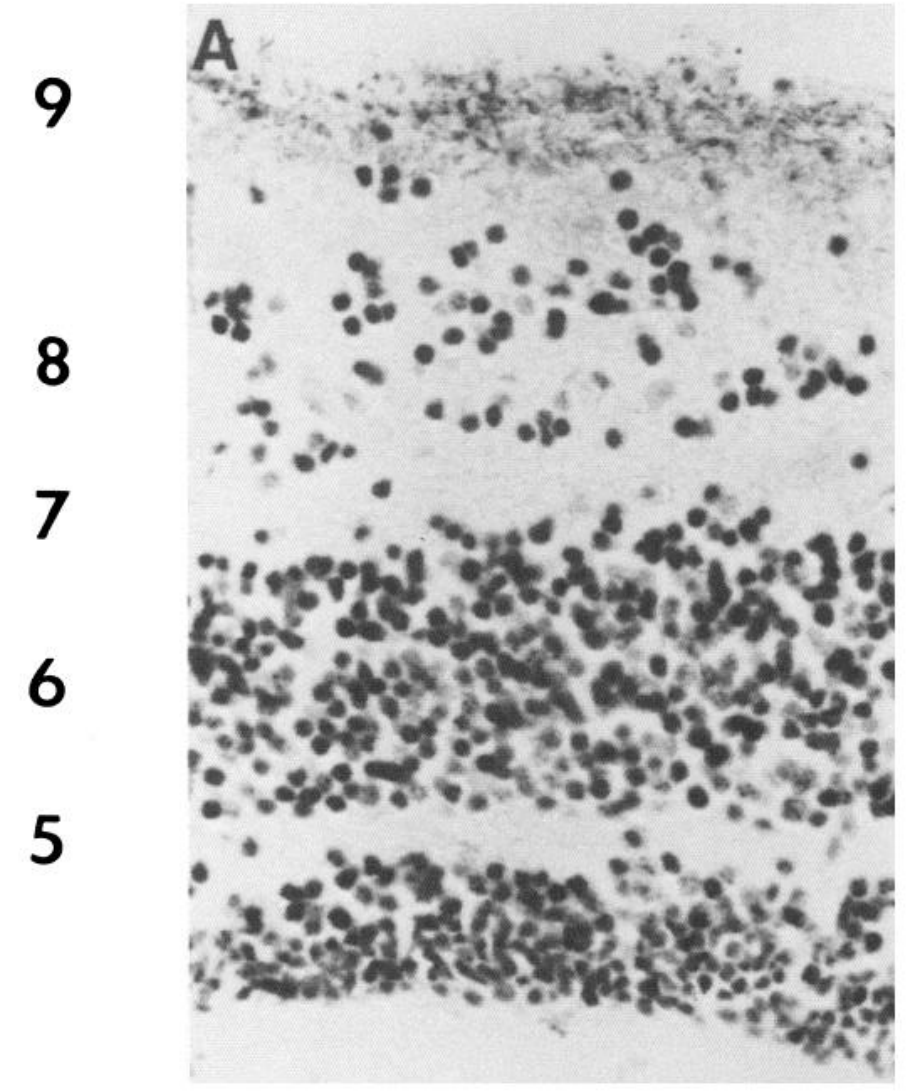

\section{B}

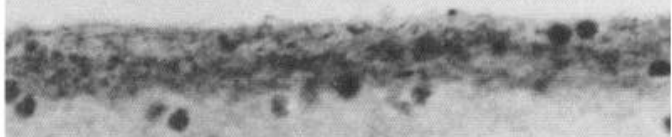

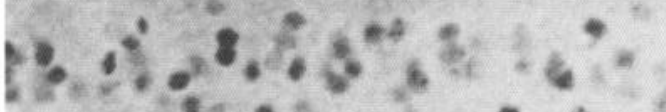

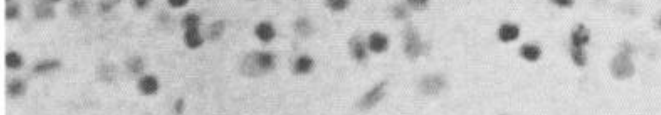

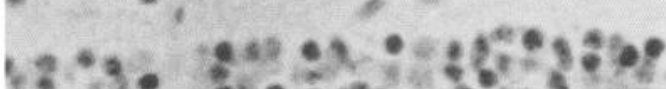

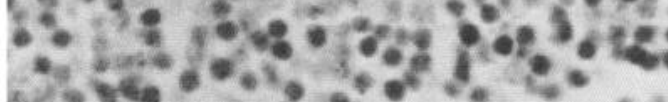

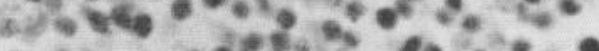

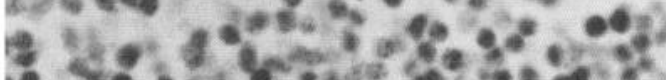

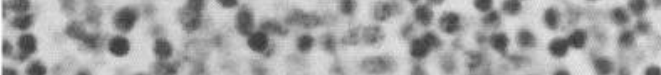

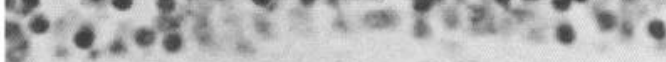

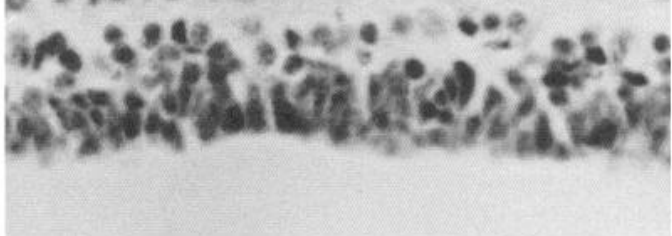

C

GCL teaseos o

GCL

INL

ONL
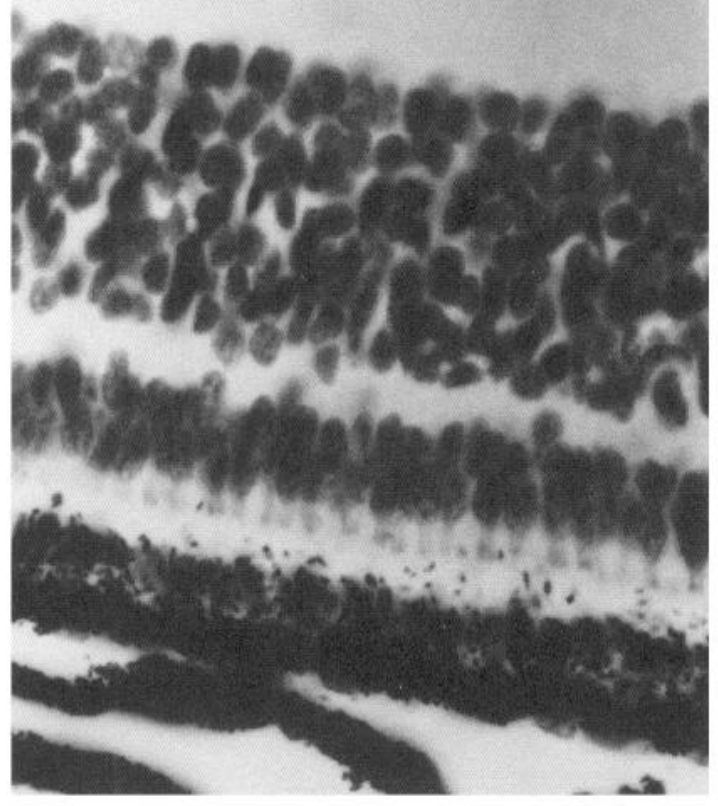

\section{D}

bi notrecto eatreva
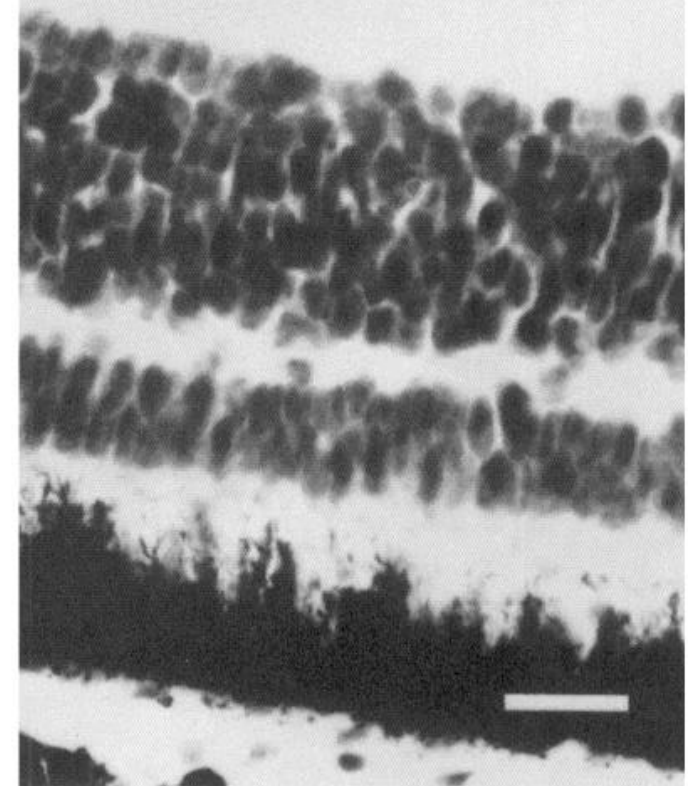

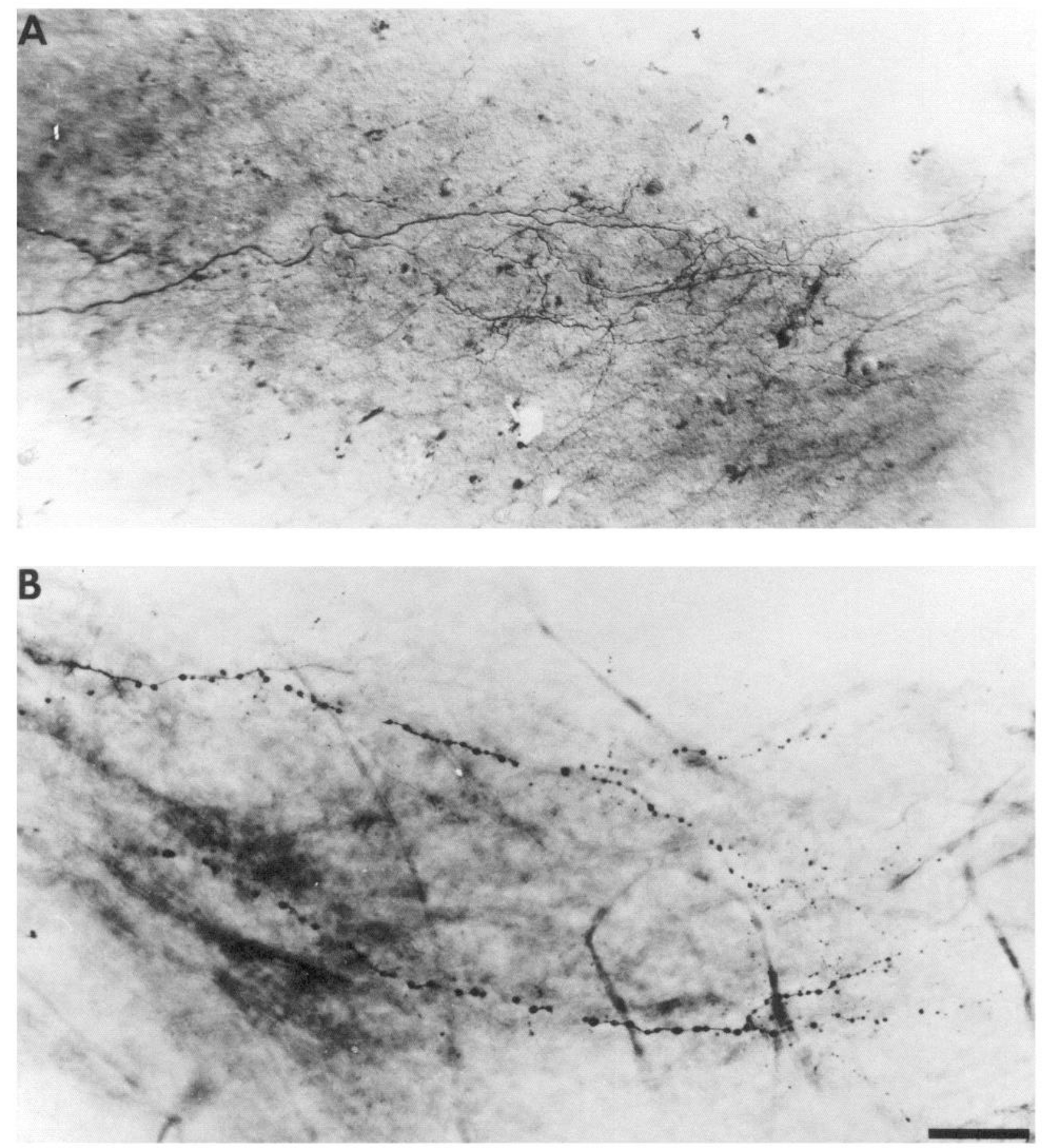

Figure 11. NMDA treatment is not toxic to retinal terminal arbors at the concentration that produces sharp stripe borders and decreased arbor density. $A$, Photograph of $3 \mathrm{HRP}$-labeled retinal arbors from an animal treated with NMDA at $10^{-4} \mathrm{M}$ in Elvax. The arbors were drawn with a camera lucida and exhibit decreased arbor density characteristic of NMDA treatment. $B$, Photograph of 2 damaged arbors from an animal treated with NMDA at $10^{-2} \mathrm{M}$ in Elvax. The arbors are beaded throughout their extent.

by increasing the probability of NMDA channel opening, as suggested by Huettner and Bean (1988). The requirement for coexposure to NMDA also suggests that the tectal NMDA channel has a relatively limited open time in untreated animals, perhaps owing to the rapid clearing of glutamate from the synaptic cleft, and that the exogenously applied NMDA significantly increases the NMDA channel activity.

\section{NMDA-induced increase in segregation}

Following chronic NMDA treatment of 2-eyed tadpoles, tectal neurons have a decreased electrophysiological sensitivity to acutely applied NMDA (Debski et al., 1989). Consequently, the threshold for detecting afferent activity as "coactive" may be increased because the amount of correlated activity necessary 
to open enough NMDA channels to stabilize 2 converging inputs should be increased. Therefore, only the synapses with the most highly correlated activity patterns would be stabilized at the same site. In 3-eyed tadpoles, a terminal has more highly correlated activity patterns with other terminals originating from the same eye and projecting to the same region of a stripe than with arbors from the other retina that project to a neighboring stripe (Law and Constantine-Paton, 1981). Therefore, NMDA treatment of 3-eyed animals should result in a relative decrease in lifetimes of synapses within the interstripe zones. Indeed, chronic NMDA treatment restricts the growth of arbors to regions where afferent activity is most highly correlated, i.e., within a stripe. The restriction is seen as a decrease in the number of processes that grow across or branch into an interstripe zone. Since some processes already extended across interstripe zones when the drug treatment was initiated, the decrease in the number of axons crossing into an interstripe zone probably represents a decreased ability of new branches to be maintained in regions of uncorrelated activity. By contrast, treatments with NMDA receptor/channel antagonists would block the cellular mechanism for the recognition of afferent coactivity. Consequently, as the retinal arbors migrate over the surface of the tectum, synapses and branches from neighboring arbors are not being selectively stabilized according to activity patterns and the eyespecific stripes gradually desegregate.

It is important to point out that NMDA treatment at any concentration tested does not cause stripe desegregation. Therefore, chronic NMDA treatment does not inactivate the ability of the system to discriminate inputs from the 2 eyes, as might be expected if exogenous NMDA either uniformly depolarized all tectal neurons or if it completely desensitized the NMDA receptors. Despite the decreased receptor sensitivity we observe and the apparent increase in the probability of channel opening resulting from chronic NMDA treatment, the maintenance of the stripe pattern indicates that relative patterns of afferent coactivity are still detected and coactive branches are still selectively stabilized. In fact, the sharper stripe borders indicate that exogenous NMDA augments the normal process of selective synapse stabilization which occurs at coactive synapses. The data are consistent with the idea that the requirement for afferent coactivity is to provide a significant depolarization of the postsynaptic membrane to relieve the voltage-dependent $\mathrm{Mg}^{2+}$ block of the NMDA channel (Mayer et al., 1984; Nowak et al., 1984) through the summation of EPSPs mediated by the non-NMDA type of EAA receptors at the coactive synapses. In other words, exogenous NMDA can only increase the stability of those synapses which are already coactive with neighboring synapses. Because of this specificity, we assume that we are augmenting the normal process of synapse stabilization when we treat with NMDA.

\section{$A$ model for the regulation of $R G C$ terminal morphology by synaptic activity}

We have shown that frog RGC arbor morphology is altered during development and by chronic in vivo drug treatment. In the first part of this paper we presented data consistent with the model that the NMDA receptor participates in the stabilization of coactive synapses. As a corollary to the synapse stabilization model, we suggest that the NMDA receptor may also play a role in the maintenance of terminal branches and the determination of neuronal structure. In particular, we hypothesize that de-

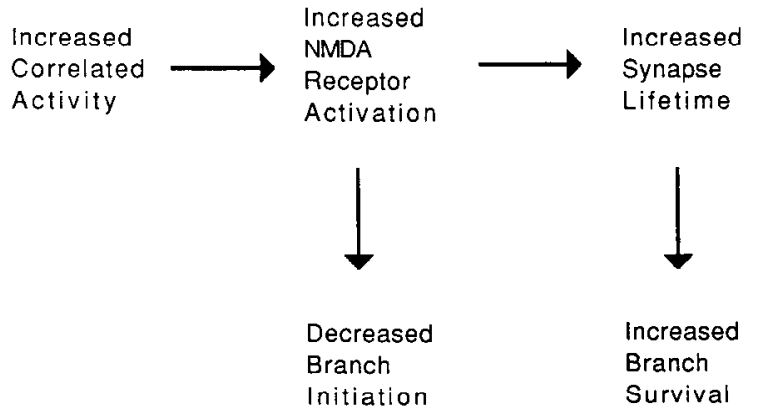

Figure 12. Diagram of the sequence of events involved in the selective stabilization of coactive synapses and the influence of synapse stabilization on axon growth. Correlated activity in RGC afferents and tectal cells leads to an increase in NMDA receptor activation at those synapses which exhibit coactivity. The consequences of NMDA receptor activation are 2-fold: it initiates the stabilization of those coactive synapses and it decreases the probability of sprouting new branches in that local region of the arbor. Since retinotectal synapses are transient, synapse stabilization may be considered as a relative increase in synapse lifetime. The increase in synapse lifetimes in turn increases the probability of survival of those branches with stable synapses. APV treatment, by blocking NMDA receptor activation throughout the arbor, results in an increased branch initiation which is counteracted by a decrease in synapse lifetime and branch survival. NMDA treatment, by decreasing the sensitivity of the retinotectal system to NMDA, raises the threshold for the recognition of coactive events and decreases NMDA receptor activation in relatively uncorrelated regions of the arbor. In this way, NMDA treatment decreases branch survival in those uncorrelated regions. Furthermore, continued presence of the agonist decreases branch initiation throughout the arbor. Independent regulation of branch initiation and synapse stabilization/branch lifetime by NMDA receptormediated mechanisms will explain the different effects of treatments with NMDA receptor antagonists and agonists.

creased NMDA receptor activation increases the probability of branch initiation and that a high degree of NMDA receptor activation is causally related to synapse stabilization and branch maintenance. The balance between branch initiation and branch retraction in subregions of the arbor based on local correlated activity patterns would shape terminal morphology. Below, we state our model and then relate it to our observations.

The model has 4 parts:

I. The degree of NMDA receptor activation is correlated with the degree of coactivity among converging synapses.

II. The stabilization (or lifetime) of synapses is correlated with the amount of NMDA receptor activation they induce.

III. A critical density of stabilized synapses is necessary for branch tips of RGC arbors to survive. This implies that branch survival correlates with the number of correlated inputs and the corresponding degree of NMDA receptor activation.

IV. The probability of branch initiation is inversely correlated with the degree of local NMDA receptor activation.

According to the model, shown schematically in Figure 12, increased NMDA receptor activation increases the stabilization of synapses and branch tips, so there would be a corresponding decrease in branch retraction. Conversely, the model predicts that under conditions of relatively low NMDA receptor activation there would be an incrcascd branch initiation, but NMDA receptor activation would be too low to stabilize the synapses on the new branches and they would retract. Note that the influence of NMDA on branch initiation may be independent 
of its influence on synapse stabilization. Electron microscopic analyses of single HRP-labeled RGC arbors in young frogs indicate that most of the synaptic contact between the retina and tectum is made through the fine branch tips that appear to be altered in the treatments we have employed (Yen and Constantine-Paton, 1988; Yen, personal communication). Therefore, we feel it is justified to associate changes in the number of branch tips with branch survival, synapse density, and synapse lifetimes, and to assume that the morphological alterations we observe reflect significant differences in retinotectal connectivity.

\section{Regulation of arbor morphology by drug treatments}

Chronic NMDA treatment. In contrast to the dramatic decrease in branch density in 3-eyed tadpoles and frogs with NMDA treatment, chronic NMDA treatment of the tecta of 2-eyed tadpoles does not change arbor branch density (Cline and Constantine-Paton, 1989). This suggests that NMDA treatment does not reduce branching by acting directly on arbors because exposure of the arbors to the drug should be identical in both normal and striped tecta. However, it raises the question of how the density of innervation influences the effect of NMDA treatment on terminal morphology. In pursuing this question, we compared RGC arbors in untreated animals with striped, or doubly innervated, versus normal, or singly innervated, tecta. Although arbors from untreated 2-eyed tadpoles cover about the same tangential area as arbors from 3-eyed tadpoles, arbors from 3-eyed tadpoles have twice the branch number and twice the branch density of arbors from untreated 2-eyed tadpoles (Cline and Constantine-Paton, 1989). There are 2 critical differences in the retinotectal convergence between singly and doubly innervated tecta which we believe account for the difference in untreated RGC terminal morphologies and for the different responses to NMDA treatment in singly and doubly innervated tecta.

The first important difference between RGC arbors in singly versus doubly innervated tecta lies in the number of synaptic contacts established by each terminal arbor. Quantitative electron microscopy of singly and doubly innervated tecta has shown that doubly innervated tecta support roughly the same number of synapses as the singly innervated tectum of the same animal (Constantine-Paton and Norden, 1986). In conjunction with analyses of RGC numbers in 3-eyed animals (Constantine-PaIon and Ferrari-Eastman, 1987), these data suggest that RGC arbors in doubly innervated tecta make many fewer synapses than their normal counterparts. Since each arbor from doubly innervated tecta also has twice the branch number, each branch must be supported by a severely reduced number of synapses compared to normal arbors. If there is a lower limit of synapse density required to maintain a branch, then the terminal branchlets in doubly innervated tecta are at greater risk of retraction than those in singly innervated tecta.

The second difference reflects the way retinal area is compressed within the striped tectum and has implications for NMDA receptor activation. Cell counts and quantitative morphometric analyses in 3-eyed frogs indicate that doubly innervated tecta have twice the normal number of RGC arbors compressed onto the tectal neuropil. But the $100 \%$ increased innervation density is compensated by only a $40 \%$ expansion of the neuropil volume (Constantine-Paton and Ferrari-Eastman, 1987). Therefore, in doubly innervated tecta, RGC arbors that would normally project to distinct but neighboring regions of the tectum are now forced to project to the same tectal regions.

Based on observations of the high degree of correlated activity in neighboring RGCs compared to nonneighboring RGCs (Arnett, 1978; Arnett and Spraker, 1981; Mastronarde, 1983a, b; Ginsberg et al., 1984), the increased overlap of arbors in doubly innervated tecta should result in a decrease in the amount of afferent coactivity per unit volume of neuropil. Decreased coactivity per unit volume of neuropil should, in turn, result in decreased NMDA receptor activation. Part IV of the activity model predicts that decreased NMDA receptor activation will produce an increased branch initiation in arbors from doubly innervated tecta compared to the degree of branch initiation in arbors from singly innervated tecta. Consistent with this, we observe a 2 -fold increase in branch density between singly and doubly innervated tecta, from 3.3 branches $/ 10^{3} \mu \mathrm{m}^{2}$ to 5.6 branches $/ 10^{3} \mu \mathrm{m}^{2}$. However, Parts II and III of the model predict that the lifetimes of the synapses and therefore of the branch tips will be short in arbors from doubly innervated tecta compared to arbors from singly innervated tecta, because decreased NMDA receptor activation decreases synapse stabilization. Our static images cannot reveal these dynamic changes that video microscopy of RGC arbors of 3-eyed animals would be expected to demonstrate. However, our model predicts an unusually rapid turnover of branch tips by increased branch initiation and shortened branch lifetimes.

We postulate that the decreased branch density in arbors from 3-eyed NMDA-treated animals results from the combined effects of the treatment working on both branch survival and branch initiation. In 3-eyed frogs, where NMDA receptors are made less sensitive by chronic NMDA treatment, increased branch retraction would occur in regions of the arbor where there is relatively little NMDA receptor activation, according to Parts II and III of the model. However, there will be some synapses within the arbor, generally in more central regions of the arbor, that have high correlations with converging neighbors. These synapses would be able to activate NMDA receptors, despite the decreased receptor scnsitivity. Moreover, these correlated synapses would be extremely effective owing to the continuous presence of agonist. Thus, as predicted by Part IV of the model, the chronic presence of NMDA would also result in a decrease in branch initiation in central regions of the arbor, where afferent coactivity is sufficient to activate NMDA receptors.

In short, we suggest that the difference in the effects of NMDA treatment in singly and doubly innervated tecta supports a role for synaptic convergence and NMDA receptors in the regulation of the RGC arbor growth. In singly innervated tecta, where a smaller area of retina projects to a unit volume of tectum, the degree of correlated activity in any region of neuropil is higher than in doubly innervated tecta. Therefore, even under conditions of lowered sensitivity, NMDA receptors throughout the arbor still have a high probability of being activated in NMDAtreated, singly innervated tecta and a net branch retraction is not observed. In addition, since each RGC arbor in a singly innervated tectum makes more synapses than its counterpart in a doubly innervated tectum, the survival of branch tips in normal arbors is less susceptible to changes in the numbers of stable synapses. The increased retinal convergence in doubly innervated tecta, by decreasing the degree of coactivity throughout the ncuropil, places the lcast correlated regions of the arbor in jeopardy. 
Chronic APV treatment. Electrophysiological experiments indicate that chronic APV treatment increases the sensitivity of tectal NMDA receptors (Debski et al., 1989). If we assume that APV treatment maintains a block of the NMDA receptors, Part III of the activity model predicts that APV treatment should decrease the lifetimc of the small terminal branches. However, Part IV of the activity model predicts that as a result of decreased NMDA receptor activation, APV treatment should also increase the probability of branch initiation. We find that APV-treated arbors have fewer branch tips than untreated arbors, but that this decrease is far less pronounced than that observed after chronic NMDA treatment. The observation is consistent with the idea that NMDA treatment both increases retraction in unstable regions of the arbor and decreases branch initiation in stable regions. In contrast, APV treatment only increases retraction, and this effect is partially counteracted by an increased branch initiation. Alternately, if APV does not effectively block the NMDA receptors when their sensitivity is increased but increases receptor sensitivity over normal levels, then the threshold for the recognition of afferent coactivity would be lowered. Thus stripes would desegregate because even poorly correlated synapses would be stabilized. On the single cell level, synapse lifetimes and branch survival would be increased according to Parts II and III of the model but branch initiation would decrease (Part IV). However, we consider this extremely improbable because the small amount of increased sensitivity that occurs is unlikely to counteract the constant presence of antagonist.

The decreased rostrocaudal length of arbors in doubly innervated tecta chronically treated with NMDA or APV suggests that the drugs influence the growth of terminal arhors. The drugs could either decrease the addition of new branches at the distal end of the arbor or increase the retraction of branches from the proximal end of the arbor. If the drugs slowed the sprouting at the distal end of the arbor, this might be detected as a relative decrease in the extent of total tectal innervation of drug-treated versus normal tectum of the same animal. After treatment of one tectal lobe with either APV-Elvax or NMDA-Elvax, and the other tectal lobe with drug-free Elvax, we did not detect a difference in the extent of tectal innervation in either APV- or NMDA-treated 2-eyed tadpoles (Cline, unpublished observation). Comparable experiments in 3-eyed tadpoles are not feasible because they require that both the control and treated tecta be innervated by the supernumerary eye to the same extent.

We have proposcd that NMDA receptors located on tcetal neurons detect correlated activity in the retinal afferents and initiate the cellular mechanisms for synapse stabilization. In this case, a signal from the postsynaptic to the presynaptic element would be necessary to initiate synapse stabilization presynaptically and to regulate branch initiation. Our data are also consistent with a model in which the regulation of branch iniliation occurs presynaptically and the detection of correlated activity and synapse stabilization are triggered postsynaptically. For instance, NMDA receptors on the terminal arbors could influence the growth of the arbors by altering growth cone mobility and branching through a calcium-mediated mechanism (Mattson and Kater, 1987). In this case, communication from the postsynaptic to the presynaptic elements would still be necessary to coordinate branch initiation and synapse stabilization on the 2 sides of the synapse. It is unlikely that the detection of afferent coactivity and selective synapse stabilization are regulated entirely by NMDA receptors located on the RGC ter- minal arbors, because axoaxonic synapses between RGC terminal arbors have not been observed (Udin et al., 1990).

\section{Generalization of the activity model}

Despite the unquestionable complexity of the activity-dependent mechanisms under study and despite the complexity of the data themselves, the model we present is supported by several observations on structural plasticity from other vertebrate visual systems. A recent study on the regeneration of the optic nerve into a half tectum in fish (Hayes and Meyer, 1988) labeled the entire RGC projection with HRP and then analyzed the superficial tectal layers using quantitative electron microscopy. When an entire retinal projection is forced to innervate a half tectum, the "compressed" projection contains the same number of retinotectal synapses as the neuropil of a normal tectum. This is similar to the maintenance of similar synaptic numbers in singly and doubly innervated tecta (Constantine-Paton and Norden, 1986) and it has been observed before by other workers in the compressed projections of goldfish (Murray et al., 1982). However, Hayes and Meyer also counted the number of fiber profiles in both the terminal entry layer and the terminal arborization layers of goldfish tecta with compressed projections. They found that the number of retinal axons entering the half tectum doubles as expected but, surprisingly, the fiber number in the tectal termination layers increased about 20 times. This suggests that, in the goldfish, as in the frog, when the retinal afferents project to a reduced target space, thereby increasing the degree of convergence, each terminal is more densely arborized. Pharmacological (Langdon and Freeman, 1986) and receptor binding (Henley and Oswald, 1988) studies in goldfish indicate that retinotectal synaptic transmission is mediated by an excitatory amino acid transmitter. These observations are consistent with Parts I and IV of the activity model we present. Namely, increased retinal convergence decreases the degree of correlation in activity patterns among afferents in local regions of neuropil, which decreases local NMDA receptor activation and leads to an increase in branch initiation. It is important to emphasize that NMDA receptor activation, in particular, or activity, in general, are not the only factors involved in determining synapse distribution. In goldfish, compression and expansion of the retinotectal map has been demonstrated to occur despite complete action potential blockade in the retina (Meyer and Wolcott, 1988).

A study in kitten visual cortex suggests a parallel with our ability to increasc cyc-specific segregation with chronic NMDA treatments. Fox and his colleagues (1989) found that visually driven synaptic transmission recorded in cortical layer IV can be blocked by APV and that the sensitivity to APV decreases between the third and fourth postnatal weeks in kittens. The timing of the naturally occurring decrease in NMDA receptor sensitivity closely parallels the critical period for normal segregation of geniculate afferents into ocular dominance columns. According to Parts II and III of our proposed model, decreased NMDA receptor activation would decrease synapse stabilization and branch lifetimes. A developmentally controlled decrease in postsynaptic NMDA sensitivity could be the critical event in "pruning" branches from arbors in regions where the degree of correlation among converging inputs is lowest. In cortical layer IV this would correspond to regions where the inputs from the 2 eyes remain relatively mixed. In addition, according to Part IV of the model, a decrease in NMDA scnsitivity throughout the arbor and the corresponding increased proba- 
bility of branch initiation may account for the profuse arborization within the ocular dominance columns (LeVay et al., 1978).

\section{Excitatory amino acid toxicity}

A well-documented response of nervous tissue to high concentrations of excitatory amino acids is cytotoxicity (Choi, 1987, 1988; Mayer and Westbrook, 1987b; Rothman and Olney, 1987; Finkbeiner and Stevens, 1988). Unambiguous toxic effects of NMDA on RGC terminal arbors were observed at NMDA concentrations of $10^{-2} \mathrm{M}$ in Elvax, a concentration 2 orders of magnitude higher than that which induces stripe sharpening and decreased RGC arbor branching. The toxic effect of high NMDA concentrations on retinal terminal arbors may be mediated directly through presynaptic receptors which have been shown to exist on rat retinal ganglion cells (Karschin et al., 1988).

It is unlikely that the results obtained with exposure of the tectum to $10^{-4} \mathrm{M}$ NMDA in Elvax are due to excitotoxicity. Concentrations of $10^{-4} \mathrm{M}$ (in Elvax) sharpen stripe borders and decrease the branch density of RGC arbors, but do not alter retinal ganglion or tectal cell number. The reduced volume of the retinotectal neuropil in NMDA-treated striped tecta is presumably due to the reduction in branching of the $\mathrm{RGC}$ arbors and a possible reduction in tectal cell dendrites. Nevertheless, RGC arbor branches often end in well-defined growth concs, indicating that the arbors are capable of growth. Another indication that the arbors are healthy is that the axon branches display a uniform diameter between branch points without any signs of the beading or blebbing seen in dying arbors.

Additional evidence that NMDA at $10^{-4} \mathrm{M}$ in Elvax is not toxic comes from studies of normal animals. RGC arbors drawn from 2-eyed tadpoles treated with NMDA at $10^{-4} \mathrm{M}$ in Elvax do not display a reduced branch density compared to controls (Cline and Constantine-Paton, 1989). Therefore, it is unlikely that the decreased branch density seen in 3-eyed animals is a toxic response of the arbors to NMDA. Finally, comparable NMDA treatments do not impair the active maintenance of the retinotopic map or interfere with retinotectal synaptic transmission in R. pipiens (Cline and Constantine-Paton, 1989; Debski et al., 1989) or visual synaptic transmission in Xenopus laevis (Scherer and Udin, 1989).

\section{Development of terminal arbor morphology}

RGC terminal arbor morphology differs dramatically in tadpoles and postmetamorphic froglets. Tadpole arbors are relatively uniform in their morphology, whereas the postmet arbors can be roughly distinguished into several morphological classes (Lazar and Szekely, 1969; Potter, 1972). The length, width, and tangential area of arbors after metamorphosis is approximately half that scen in tadpole arbors, yet they maintain the same number of branch endings as before metamorphosis. Thus, in the young frog, the branch density of RGC terminal arbors is twice that seen in the tadpoles. Our data suggest that the transition from the diffuse tadpole-type arbor to the concentrated frog arbor is rapid and probably occurs within the first month after metamorphosis.

It is possible that developmentally programmed changes in NMDA sensitivity underlie the metamorphic changes we observe in RGC arbors from tadpoles and postmetamorphic frogs. For example, a naturally occurring decrease in postsynaptic NMDA sensitivity might cause the reduction in tangential area seen after metamorphosis. Furthermore, as suggested above for the maturing mammalian visual cortex, if NMDA receptor activation falls sufficiently low throughout the arbor, then the postulated net increase in branch initiation could explain the increased branch density within the pruned arbor. However, it is again necessary to add the caveat that the increased complexity of terminal arbors after metamorphosis does not necessarily arise from a local postsynaptic-presynaptic interaction, involving sprouting factors or neural activity. Neuronal processes have been shown to sprout in response to hormones (Arnold and Gorski, 1984; Hoskins and Grobstein, 1984; Weeks and Levine, 1990). Consequently, the increased thyroxine titer during metamorphosis (Etkin, 1935) could itself cause the observed increase in branching in the terminal arbors.

In summary, we have shown that the RGC terminal arbors in the frog undergo structural modifications during normal development. Furthermore, we have shown that structural modifications can be induced in vivo either as a result of increasing innervation density or by specific drug treatments. We interpret the data to mean that terminal arbor morphology can be modified in response to local endogenous changes in patterns of afferent coactivity. We suggest that the NMDA receptor plays a kcy rolc in recognizing afferent coactivity and translating it into structural modifications. It accomplishes this by modulating 2 ongoing events: (1) synapse lifetimes and thus branch survival and (2) the probability of branch initiation or sprouting.

\section{References}

Arnett, D. W. (1978) Statistical dependence between neighboring retinal ganglion cells in goldfish. Exp. Brain Res. 32: 49-53.

Arnett, D., and T. E. Spraker (1981) Cross-correlation analysis of the maintained discharge of rabbit retinal ganglion cell. J. Physiol. (Lond.) 317: $29-47$.

Arnold, A. P., and R. A. Gorski (1984) Gonadal steroid induction of structural sex differences in the central nervous system. Annu. Rev. Neurosci. 7: 413-442.

Choi, D. W. (1987) Ionic dependence of glutamate neurotoxicity. J. Neurosci. 7: 369-379.

Choi, D. W. (1988) Glutamate neurotoxicity and diseases of the nervous system. Neuron 1: 623-634.

Cline, H. T., and M. Constantine-Paton (1989) NMDA receptor antagonists disrupt the retinotectal topographic map. Neuron $13: 413$ 426.

Cline, H. T., E. Debski, and M. Constantine-Paton (1987) NMDA receptor antagonist desegregates eye-specific stripes. Proc. Natl. Acad. Sci. USA 84: $4342-4345$.

Constantine-Paton, M., and P. Ferrari-Eastman (1987) Pre- and postsynaptic correlates of interocular competition and segregation in the frog. J. Comp. Neurol. 255: 178-195.

Constantine-Paton, M., and J. J. Norden (1986) Development of order in the visual system. In Cell and Developmental Biology of the Eve, S. R. Hilfer and J. B. Sheffield, eds., Springer-Verlag, New York.

Constantine-Paton, M., H. T. Cline, and E. Debski (1990) Patterned activity, synaptic convergence and the NMDA receptor in developing visual pathways. Annu. Rev. Neurosci. 13 (in press).

Cook, J. E. (1988) Topographic refinement of the goldfish retinotectal projection: Sensitivity to stroboscopic light at different periods during optic nerve regeneration. Exp. Brain Res. 70: 109-116.

Cotman, C. W., D. T. Monaghan, and A. H. Ganong (1988) Excitatory amino acid neurotransmission: NMDA receptors and Hebb-type synaptic plasticity. Annu. Rev. Physiol. 11: 61-80.

Davies, S. N., D. Martin, J. D. Millar, J. A. Aram, J. Church, and D. Lodge (1988) Differences in results from in vivo and in vitro studies on the use-dependency of $N$-methylaspartate antagonism by MK- 801 and other phencyclidine receptor ligands. Eur. J. Pharmacol. 145 . 141-145.

Debski, E. A., and M. Constantine-Paton (1988) The effects of glutamate receptor agonists and antagonists on the evoked potential in Rana pipiens. Proc. Soc. Neurosci. 14: 674. 
Debski, E. A., H. T. Cline, and M. Constantine-Paton (1987) Kynurenic acid blocks retinal-tectal transmission in Rana pipiens. Proc. Soc. Neurosci. 13: 1691.

Debski, E. A., H. T. Cline, and M. Constantine-Paton (1989) Chronic application of NMDA or APV affects the NMDA sensitivity of the evoked tectal response in Rana pipiens. Proc. Soc. Neurosci. 15: 495

Dubin, M. W., L. A. Stark, and S. M. Archer (1986) A role for actionpotential activity in the development of neural connections in the kitten retinogeniculate pathway. J. Neurosci. 6: 1021-1036.

Etkin, W. (1935) The mechanisms of anuran metamorphosis. I. Thyroxine concentration and the metamorphic pattern. J. Exp. Zool. 71 317-340.

Finkbeiner, S., and C. F. Stevens (1988) Applications of quantitative measurements for assessing glutamate neurotoxicity. Proc. Natl. Acad. Sci. USA 85: 4071-4074.

Fox, B. E. S., and S. E. Fraser (1987) Excitatory amino acids in the retino-tectal system of Xenopus laevis. Proc. Soc. Neurosci. 13: 766.

Fox, K., H. Sato, and N. Daw (1989) The location and function of NMDA receptors in cat and kitten visual cortex. J. Neurosci. 9: 24432454

Gaze, R. M., M. J. Keating, A. Ostberg, and S.-H. Chung (1979) The relationship between retinal and tectal growth in larval Xenopus: Implications for the development of retino-tectal projection. J. Embryol. Exp. Morph. 53: 103-143.

Ginsberg, K. S., J. A. Johnsen, and M. W. Levine (1984) Common noise in the firing of neighboring ganglion cells in goldfish retina. $J$. Physiol. (Lond.) 351: 433-444.

Greenamyre, J. T., J. M. M. Olson, J. B. Penney, and A. B. Young (1985) Autoradiographic characterization of $N$-methyl-D-aspartate-, quisqualate-, and kainate-sensitive glutamate binding sites. J. Pharmacol. Exp. Ther. 233: 254-263.

Harris, L., and D. Purves (1989) Rapid remodeling of sensory endings in the corneas of living mice. J. Neurosci. 9: 2210-2214.

Hayes, W. P., and R. L. Meyer (1988) Optic synapse number but not density is constrained during regeneration onto surgically halved tectum in goldfish: HRP-EM evidence that optic fibers compete for fixed numbers of postsynaptic sites in the tectum. J. Comp. Neurol. 274 $539-559$.

Henley, J. M., and R. E. Oswald (1988) Characterization and regional distribution of glutamatergic and cholinergic ligand binding sites in goldfish brain. J. Neurosci. 8: 2101-2107.

Hicks, T. P. (1987) Excitatory amino acid pathways in cerebral cortex In Excitatory Amino Acid Transmission, T. P. Hick, D. Lodge, and H. McLennan, eds., pp. 373-380, Liss, New York.

Hoskins, S. G., and P. Grobstein (1984) Induction of the ipsilateral retinothalamic projection in Xenopus laevis by thyroxine. Nature 307: 730-733.

Hubel, D. H., T. N. Wiesel, and S. LeVay (1977) Plasticity of ocular dominance columns in monkey striate cortex. Phil. Trans. R. Soc. Ser. B 278: 377-409.

Huettner, J., and B. Bean (1988) Block of $N$-methyl-D-aspartate activated current by the anticonvulsant MK801: Sclcctive binding to open channels. Proc. Natl. Acad. Sci. USA 85: 1307-1311.

Karschin, A., E. Aizenman, and S. A. Lipton (1988) The interaction of agonists and noncompetitive antagonists at the excitatory amino acid receptors in rat retinal ganglion cells in vitro. J. Neurosci. 8: 28952906.

Kleinschmidt, A., M. F. Bear, and W. Singer (1987) Blockade of NMDA receptors disrupts experience-dependent plasticity of kitten striate cortex. Science 238: 355-358.

Langdon, R. B., and J. A. Freeman (1986) Antagonists of glutaminergic neurotransmission block retino-tectal transmission in goldfish. Brain Res. 398: 169-174.

Law, M. I., and M. Constantine-Paton (1981) Anatomy and physiology of experimentally produced striped tecta. J. Neurosci. 1:741759.

Lazar, Gy., and Gy. Szekely (1969) Distribution of optic terminals in the different optic centers of the frog. Brain Res. 16:1-16.

LeVay, S., M. D. Stryker, and C. J. Shatz (1978) Ocular dominance columns and their development in layer IV of the cat's visual cortex. J. Comp. Neurol. 179: 223-224.

MacDermott, A. B., M. L. Mayer, G. L. Westbrook, S. J. Smith, and J. L. Barker (1986) NMDA receptor activation increases cytoplasmic calcium concentration in cultured spinal cord neurons. Nature 321: 519-522.
Mastronarde, D. N. (1983a) Correlated firing of cat retinal ganglion cells. I. Spontaneously active inputs to X-and Y-cells. J. Neurophysiol. 49: 303-324.

Mastronarde, D. N. (1983b) Interactions between ganglion cells in cat retina. J. Neurophysiol. 49: 350-365.

Mattson, M. P. (1988) Neurotransmitters in the regulation of neuronal cytoarchitecture. Brain Res. Rev. 13: 179-212.

Mattson, M. P., and S. B. Kater (1987) Calcium regulation of neurite elongation and growth cone motility. J. Neurosci. 7: 4034-4043.

Mayer, M. L., and G. L. Westbrook (1987a) The physiology of excitatory amino acids in the vertebrate central nervous system. Prog. Neurobiol. 28: 197-276.

Mayer, M. L., and G. L. Westbrook (1987b) Cellular mechanisms underlying excitotoxicity. Trends Neurosci. 10:59-60.

Mayer, M. L., G. L. Westbrook, and P. B. Guthrie (1984) Voltagedependent block by $\mathrm{Mg}^{++}$of NMDA responses in spinal cord neurones. Nature (Lond.) 309: 261-263.

McDonald, J. W., H. T. Cline, M. Constantine-Paton, W. E. Maragos, M. V. Johnston, and A. B. Young (1989) Quantitative autoradiographic localization of NMDA, quisqualate and PCP receptors in the frog tectum. Brain Res. 482: 155-159.

Meyer, R. L. (1983) Tetrodotoxin blocks the formation of ocular dominance columns in goldfish. Science 218: 589-591.

Meyer, R. L., and L. L. Wolcott (1988) Compression and expansion without impulse activity in the retinotectal projection of the goldfish. J. Neurobiol. 18: 549-567.

Miller, K. D., J. B. Keller, and M. P. Stryker (1989a) Ocular dominance column development: Analysis and simulation. Science 245: 605615.

Miller, K. D., B. Chapman, and M. P. Stryker (1989b) Visual responses in adult cat visual cortex depend on $N$-methyl-D-aspartate receptors. Proc. Natl. Acad. Sci. USA 86: 5183-5187.

Monaghan, D. T., and C. W. Cotman (1985) Distribution of NMDAsensitive L-3H-glutamate binding sites in rat brain as determined by quantitative autoradiography. J. Neurosci. 5: 2909-2919.

Murray, M., S. Sharma, and M. A. Edwards (1982) Target regulation of synaptic number in the compressed retinotectal projection of goldfish. J. Comp. Neurol. 209: 374-385.

Nowak, L., P. Bregestovski, P. Ascher, A. Herbert, and A. Provchiantz (1984) Magnesium gates glutamate-activated channels in mouse central neurones. Nature (Lond.) 307: 462-465.

Potter, H. D. (1972) Terminal arborizations of retinotectal axons in the bullfrog. J. Comp. Neurol. 144: 269-284.

Purves, D., R. D. Hadley, and J. T. Voyvodic (1986) Dynamic changes in the dendritic geometry of individual neurons visualized over periods of up to three months in the superior cervical ganglion of living mice. J. Neurosci. 6: 1051-1060.

Purves, S., J. T. Voyvodic, L. Magrassi, and H. Yawo (1987) Nerve terminal remodeling visualized in living mice by repeated examination of the same neuron. Science 238: 1122-1126.

Reh, T., and M. Constantine-Paton (1984) Retinal ganglion cells change their projection sites during larval development of Rana pipiens. $\mathrm{J}$ Neurosci. 4: 442-457.

Reh, T. A., and M. Constantine-Paton (1985) Eye-specific segregation requires neural activity in three-eyed Rana pipiens. J. Neurosci. 5: $1132-1143$

Rothman, S. M., and J. W. Olney (1987) Excitotoxicity and the NMDA receptor. Trends Neurosci. 10: 299-302.

Scherer, W. J., and S. B. Udin (1989) $\mathrm{N}$-methyl-D-aspartate antagonists prevent interaction of binocular maps in Xenopus tectum. J. Neurosci. 9: 3837-3843.

Schmidt, J. T. (1990) Long-term potentiation and activity-dependent retinotopic sharpening in the regenerating retinotectal system in goldfish: Common sensitive period and sensitivity to NMDA blockers. J. Neurosci. 10: 233-246.

Schmidt, J. T., and D. L. Edwards (1983) Activity sharpens the map during regeneration of the retinotectal projection in goldfish. Brain Res. 209: 29-39.

Shatz, C. J., and M. P. Stryker (1988) Prenatal tetrodotoxin infusion blocks segregation of retinogeniculate afferents. Science 242: 87-89.

Silberstein, G. B., and C. W. Daniel (1982) Elvax 40P implants: Sustained, local release of bioactive molecules influencing mammary ductal development. Dev. Biol. 93: 272-278.

Snedecor, G. W., and W. G. Cochran (1967) Statistical Methods, lowa State Univ. Press, Ames. 
Stirling, R. V., and E. G. Merrill (1987) Functional morphology of frog retinal ganglion cells and their central projections: The dimming detectors. J. Comp. Neurol. 258: 477-495.

Stretavan, D. W., and C. J. Shatz (1986) Prenatal development of retinal ganglion cell axons: Segregation into eye-specific layers within the cat's lateral geniculate nucleus. J. Neurosci. $6: 234-251$.

Stryker, M. P., and W. A. Harris (1986) Binocular impulse blockade prevents the formation of ocular dominance columns in cat visual cortex. J. Neurosci. 6: 2117-2133.

Sutula, T., X.-X. He, J. Cavazos, and G. Scott (1988) Synaptic reorganization in the hippocampus induced by abnormal functional activity. Science 239: 1147-1150.

Taylor, A. C., and J. J. Kollros (1946) Stages in the development of Rana pipiens larvae. Anat. Res. 94: 7-23.

Udin, S. B., and J. W. Fawcett (1988) Formation of topographic maps. Annu. Rev. Neurosci. 11:289-327.

Udin, S. B., M. D. Fisher, and J. J. Norden (1990) Ultrastructure of the crossed isthmotectal projection in Xenopus frogs. J. Comp. Neurol. (in press).
Voyvodic, J. T. (1987) Development and regulation of dendrites in rat superior cervical ganglion. J. Neurosci. 7: 904-912.

Weeks, J. C., and R. B. Levine (1990) Postembryonic neuronal plasticity and its hormonal control during insect metamorphosis. Annu. Rev. Neurosci. 13 (in press).

Whitelaw, V. A., and J. D. Cowan (1981) Specificity and plasticity of retinotectal connections: A computational model. J. Neurosci. 1: 13691387.

Wigston, D. J. (1989) Remodeling of neuromuscular junctions in adult mouse soleus. J. Neurosci. 9: 639-647.

Wong, E. H. F., J. A. Kemp, T. Priestly, A. R. Knight, G. N. Woodruff, and I. I. Iversen (1986) The anticonvulsant MK-801 is a potent $N$-methyl-D-aspartate antagonist. Proc. Natl. Acad. Sci. USA 83: 7104 7108.

Yen, L.-H., and M. Constantine-Paton (1988) EM analysis of single retinal ganglion cell terminals in developing Rana pipiens. Proc. Soc. Neurosci. 14: 674. 